\title{
Coupling of Precipitation and Cloud Structures in Oceanic Extratropical Cyclones to Large-Scale Moisture Flux Convergence
}

\author{
SUN WONG \\ Jet Propulsion Laboratory, California Institute of Technology, Pasadena, California \\ CATHERINE M. NAUD \\ Applied Physics and Applied Mathematics, Columbia University, New York, New York \\ Brian H. KAHN, LONGTAO Wu, AND ERIC J. FETZER \\ Jet Propulsion Laboratory, California Institute of Technology, Pasadena, California
}

(Manuscript received 28 February 2018, in final form 25 September 2018)

\begin{abstract}
Precipitation (from TMPA) and cloud structures (from MODIS) in extratropical cyclones (ETCs) are modulated by phases of large-scale moisture flux convergence (from MERRA-2) in the sectors of ETCs, which are studied in a new coordinate system with directions of both surface warm fronts (WFs) and surface cold fronts (CFs) fixed. The phase of moisture flux convergence is described by moisture dynamical convergence $Q_{\text {cnvg }}$ and moisture advection $Q_{\text {advt }}$. Precipitation and occurrence frequencies of deep convective clouds are sensitive to changes in $Q_{\text {cnvg }}$, while moisture tendency is sensitive to changes in $Q_{\text {advt. }}$. Increasing $Q_{\text {cnvg }}$ and $Q_{\text {advt }}$ during the advance of the WF is associated with increasing occurrences of both deep convective and high-level stratiform clouds. A rapid decrease in $Q_{\text {advt }}$ with a relatively steady $Q_{\text {cnvg }}$ during the advance of the $\mathrm{CF}$ is associated with high-level cloud distribution weighting toward deep convective clouds. Behind the CF (cold sector or area with polar air intrusion), the moisture flux is divergent with abundant lowand midlevel clouds. From deepening to decaying stages, the pre-WF and WF sectors experience high-level clouds shifting to more convective and less stratiform because of decreasing $Q_{\text {advt }}$ with relatively steady $Q_{\text {cnvg, }}$, and the CF experiences shifting from high-level to midlevel clouds. Sectors of moisture flux divergence are less influenced by cyclone evolution. Surface evaporation is the largest in the cold sector and the CF during the deepening stage. Deepening cyclones are more efficient in poleward transport of water vapor.
\end{abstract}

\section{Introduction}

A key question related to climate sensitivity is how clouds and precipitation respond to changes in the largescale circulation (Bony et al. 2015). A more direct and fundamental question is how clouds and precipitation respond to changes in moisture flux convergence induced by changes in the large-scale circulation. In this work, we investigate moisture balance in extratropical cyclones (ETCs) to quantify coupling of precipitation and cloud processes to the large-scale circulation not only because ETCs are dominant weather patterns responsible for extreme precipitation in the extratropics (Pfahl and Wernli 2012) but also because different sectors of ETCs have

\footnotetext{
Corresponding author: Sun Wong, sun.wong@jpl.nasa.gov
}

different dynamical conditions for cloud and precipitation formation (e.g., Houze and Hobbs 1982).

Because it is still unclear how precipitation in ETCs will evolve in a changing climate (e.g., Li et al. 2014; Yettella and Kay 2017), recent studies of ETCs through composites mainly focus on unraveling the interactions between clouds, precipitation, and the underlying largescale dynamics and/or thermodynamics (e.g., Bauer and Del Genio 2006; Chang and Song 2006; Field and Wood 2007; Naud et al. 2010, 2012, 2013, 2015; Booth et al. 2013, 2018; Pfahl and Sprenger 2016). Using combined CloudSat (Stephens et al. 2002) and Cloud-Aerosol Lidar and Infrared Pathfinder Satellite Observations (CALIPSO; Winker et al. 2009) data, Naud et al. (2010, 2015) and Booth et al. (2013) described the cloud vertical structures across transects of either surface warm or cold fronts in ETCs and investigated their relationships 
with large-scale dynamic and thermodynamic variables. Detailed investigations of warm frontal cloud structures indicated that the cloudiness in the vertical tilting of warm fronts increases with the upper-tropospheric vertical velocity ahead of the surface warm fronts and also with the background moisture content (Naud et al. 2010; Booth et al. 2013; Govekar et al. 2014), implying a relationship between cloud formation and the uplifting mechanism of warm conveyor belts (WCBs; Browning 1986; Schemm et al. 2013). These studies raise a further question of how internal variation of moisture flux convergence of ETCs influences the internal variation in cloud structures.

Precipitation averaged over the area of ETCs has been correlated to the moisture fluxes in WCBs (Field and Wood 2007; Pfahl and Sprenger 2016). Rudeva and Gulev (2011) demonstrated that deepening cyclones have larger differences in extreme values of surface turbulent fluxes and precipitation than decaying cyclones. Polly and Rossow (2016) illustrated that the extreme values (maximum vs minimum) within the ETCs largely depend on cyclone depths. Both studies suggest changes in cloud and precipitating structures within the ETCs during cyclone evolution. This paper aims at further connecting these changes to moisture flux convergence within the ETCs.

In this investigation, we focus on structural changes of clouds and precipitation among different sectors of ETCs throughout their life cycle and relate the changes to phases of large-scale moisture flux convergence in the sectors. Sectors of ETCs are defined in a new coordinate system (referred to as ETC coordinates) in which directions of both surface warm and cold fronts are fixed to facilitate composites revealing the structures of both fronts. Phases of moisture flux convergence are shown in a two-dimensional phase space introduced by Wong et al. (2016). Composites and statistics of long-term satellite records of macroscopic cloud properties and precipitation surrounding ETCs are then linked to phases of moisture flux convergence. To avoid complexity caused by topographical or coastline effects, we focus on oceanic ETCs with centers at $30^{\circ}-50^{\circ}$ latitudes in both hemispheres for 2007-15 (including 14087 ETCs).

\section{Satellite and reanalysis data}

Collection-6 level 2 retrievals of cloud-top pressure (CTP) and cloud optical depth (COD) from the Moderate Resolution Imaging Spectroradiometer (MODIS) onboard the Aqua platform (King et al. 2003, 2013; Platnick et al. 2003; Ackerman et al. 2008; Frey et al. 2008; Menzel et al. 2008) are used to represent cloud macroscopic properties. We average MODIS nonzero COD from $1-\mathrm{km}$ pixels to $5-\mathrm{km}$ resolution and use the CTP provided at the same resolution.
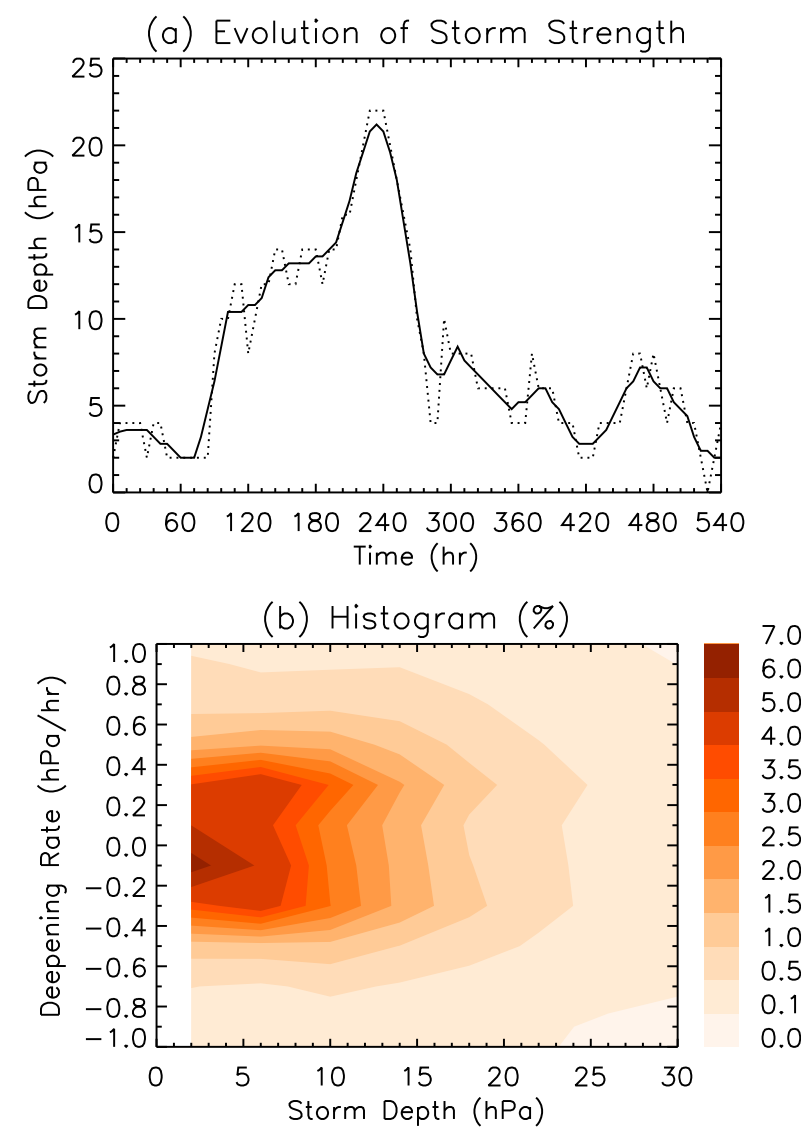

FIG. 1. (a) Temporal evolution of a typical storm's depth along its track. The dashed line is at 6-hourly resolution, and the solid line is the filtered evolution by a 1-day window mean. (b) Histogram of storm deepening rates and depths of ETCs with centers at latitudes of $30^{\circ}-50^{\circ}$ in both hemispheres for 2007-15.

Following Rossow and Schiffer (1999), we use the MODIS-retrieved CTP and COD as proxies to classify clouds into nine categories. In terms of CTP, there are high-level $(\mathrm{CTP}<440 \mathrm{hPa})$, midlevel $(440<\mathrm{CTP}<$ $680 \mathrm{hPa})$, and low-level $(\mathrm{CTP}>680 \mathrm{hPa})$ clouds. In terms of $\mathrm{COD}$, there are thin $(\mathrm{COD}<3.6)$, medium-thick $(3.6<\mathrm{COD}<23)$, and thick $(\mathrm{COD}>23)$ clouds (see Fig. 5a, second column). Therefore, the nine cloud types are cirrus ( $\mathrm{Ci}$; high, thin), cirrostratus (Cs; high, medium thick), deep convective ( $\mathrm{Cb}$; high, thick), altocumulus (Ac; midlevel, thin), altostratus (As; midlevel, medium thick), nimbostratus (Ns; midlevel, thick), cumulus $(\mathrm{Cu}$; low, thin), stratocumulus (Sc; low, medium thick), and stratus (St; low, thick). The cases that cannot be classified are simply identified in this study as "clear," which may include undetected thin cirrus or partially cloudy pixels for which CODs are not retrieved. We note that such representation of cloud-type combinations using passive sensors (MODIS or ISCCP) tends to mask the existence of lower-level clouds under thick high clouds (Chen and 

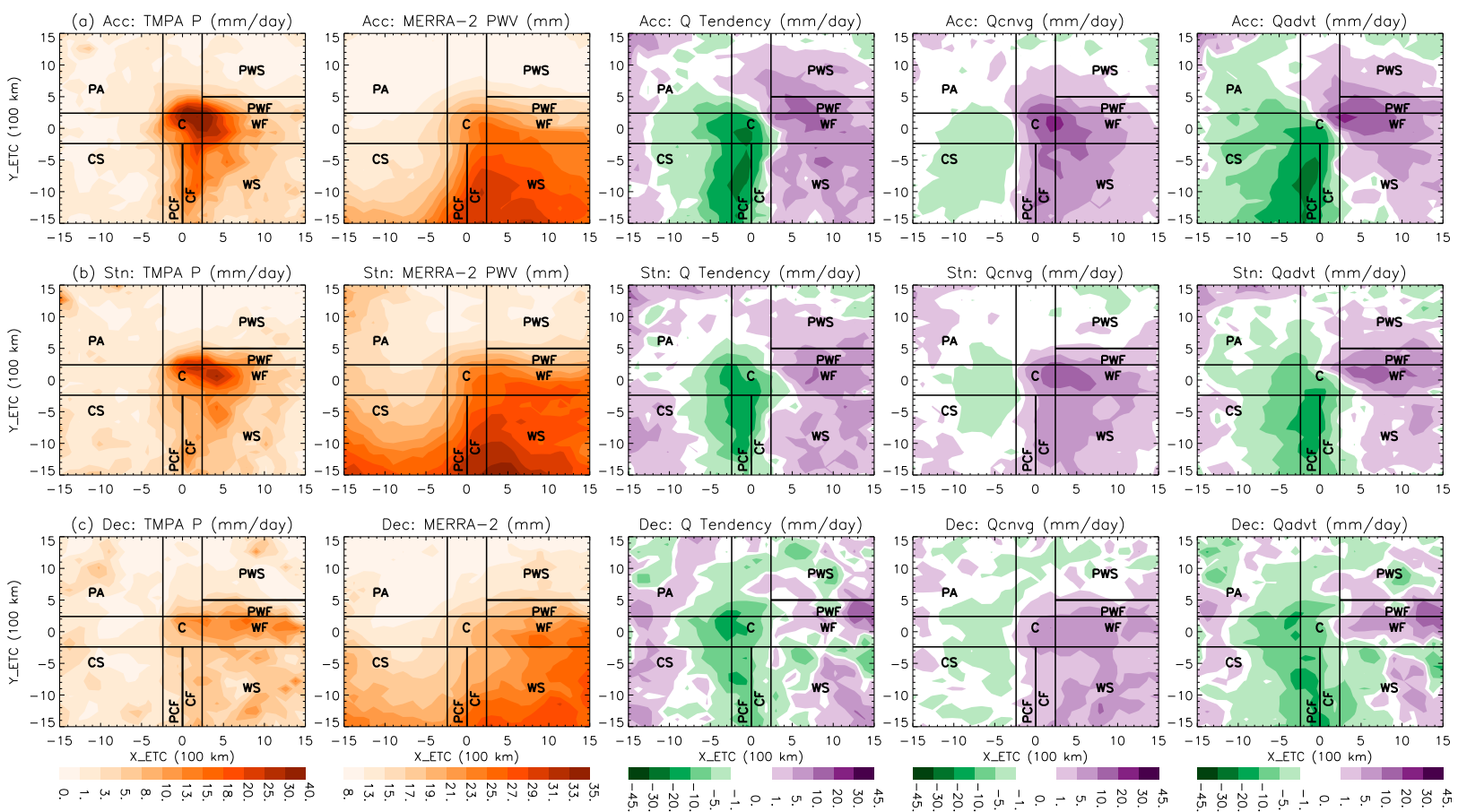

FIG. 2. Composites in the ETC coordinate (see section $3 \mathrm{c}$ and the appendix for definitions) of (first column) TMPA $P$ (mm day ${ }^{-1}$ ), (second column) MERRA-2 PWV (mm), (third column) MERRA-2 $\partial Q / \partial t\left(\mathrm{~mm} \mathrm{day}^{-1}\right)$, (fourth column) $Q_{\mathrm{cnvg}}\left(\mathrm{mm} \mathrm{day}^{-1}\right)$, and (fifth column) $Q_{\text {advt }}\left(\mathrm{mm} \mathrm{day}^{-1}\right.$ ) for cyclones with (a) deepening (Acc), (b) neutral (Stn), and (c) decaying (Dec) stages (see section 3c for definitions of these cyclone development stages). Also indicated are the boundaries of nine sectors as defined in Table 1.

Del Genio 2009; Marchand et al. 2010; Wong et al. 2016; Wang et al. 2016). Therefore, this study tends to observe fewer low-level clouds behind the surface warm fronts compared to previous studies using CloudSat/CALIPSO (e.g., Naud et al. 2010).

We use the Tropical Rainfall Measuring Mission (TRMM) Multisatellite Precipitation Analysis (TMPA; or TRMM 3B42, version 7; Huffman et al. 2007; Huffman and Bolvin 2009) for our precipitation composites. The TMPA product is constructed by combining microwave and infrared precipitation estimates and is available at 3 -hourly intervals and $0.25^{\circ} \times 0.25^{\circ}$ spatial resolution, covering the globe from $50^{\circ} \mathrm{S}$ to $50^{\circ} \mathrm{N}$. Compared to Global Precipitation Climatology Project daily product, TMPA has a wider rain-rate spectrum with more frequent detection of both light and extreme heavy precipitation (Wong and Behrangi 2018).

Large-scale atmospheric conditions that correspond to the MODIS retrievals are obtained from the NASA Modern-Era Retrospective Analysis for Research and Applications, version 2 (MERRA-2; Bosilovich et al. 2015; Gelaro et al. 2017) at $0.5^{\circ}$ latitude $\times 0.625^{\circ}$ longitude horizontal resolution by matching the MERRA-2 grid cell and time that are closest to the MODIS observational location and time. Then, TMPA data within the collocated MERRA-2 grid cells are chosen to represent the corresponding precipitation.

\section{ETC coordinates and moisture flux convergence phase space}

\section{a. Identification of warm and cold fronts}

ETC center locations are obtained with the NASA Modeling, Analysis, and Prediction (MAP) Climatology of Midlatitude Storminess (MCMS) algorithm (Bauer et al. 2016). The algorithm uses the 6-hourly sea level pressure output of ERA-Interim (Dee et al. 2011) to identify extratropical cyclone center locations and tracks.

Separately, surface cold and warm fronts in each ETC are identified using the MERRA-2 temperature and winds. MERRA-2 has a finer horizontal spatial resolution than ERA-Interim that allows more precise front delineation. The fronts are determined at 6-hourly temporal resolution, consistent with the MCMS dataset, using an algorithm based on two published methods: a temperature gradient method (Hewson 1998) to locate and delineate surface warm and cold fronts and a method based on wind direction changes (Simmonds et al. 2012) to determine cold fronts with weaker baroclinicity. The algorithm is described in detail by Naud 
TABLE 1. Definitions of nine sectors in ETCs in the ETC coordinate system.

\begin{tabular}{ll}
\hline \hline Sector & \multicolumn{1}{c}{ ETC coordinate ranges } \\
\hline PWS & $240<x_{\text {ETC }}<1500 \mathrm{~km}, 500<y_{\text {ETC }}<1500 \mathrm{~km}$ \\
PWF & $240<x_{\text {ETC }}<1500 \mathrm{~km}, 240<y_{\text {ETC }}<500 \mathrm{~km}$ \\
WF & $240<x_{\text {ETC }}<1500 \mathrm{~km},-240<y_{\text {ETC }}<240 \mathrm{~km}$ \\
WS & $240<x_{\text {ETC }}<1500 \mathrm{~km},-1500<y_{\text {ETC }}<-240 \mathrm{~km}$ \\
CF & $0<x_{\text {ETC }}<240 \mathrm{~km},-1500<y_{\text {ETC }}<-240 \mathrm{~km}$ \\
PCF & $-240<x_{\text {ETC }}<0 \mathrm{~km},-1500<y_{\text {ETC }}<-240 \mathrm{~km}$ \\
CS & $-1500<x_{\text {ETC }}<-240 \mathrm{~km},-1500<y_{\text {ETC }}<-240 \mathrm{~km}$ \\
PA & $-1500<x_{\text {ETC }}<-240 \mathrm{~km}, 240<y_{\text {ETC }}<1500 \mathrm{~km}$ \\
C & $-240<x_{\text {ETC }}<240 \mathrm{~km},-240<y_{\text {ETC }}<240 \mathrm{~km}$ \\
\hline
\end{tabular}

et al. (2010, 2016). The frontal detection method is set to distinguish between cold and warm fronts, but does not recognize systems that are undergoing occlusion. Consequently, occluded fronts are misidentified as either cold or warm fronts; preliminary tests and this study indicate that most often the occluded front is classified as a warm front. However, in the rest of this study, we use all the detected warm fronts, including those that might in fact be occluded fronts.

\section{b. Cyclone depth and deepening rate}

Following Polly and Rossow (2016), the depth of an ETC is measured by the difference between the SLP at the cyclone center and the outermost closed SLP contour. The depth of each ETC is determined for each 6-hourly time step along its track. Figure 1a shows an example of time evolution of the depth of a typical ETC. The deepening rate is defined by the time derivative of its depth smoothed by a 1-day window-mean filter (i.e., the slope of the solid line in Fig. 1a). A joint histogram of cyclone deepening rate versus its depth is shown in Fig. 1b, in which minima in the evolution curve are excluded. To find the minima, we choose segments of the curve with positive second derivatives and absolute deepening rates less than $0.24 \mathrm{hPa} \mathrm{day}^{-1}$, half of the standard deviation. Cyclone snapshots close to their beginning of the genesis and end of the lysis stages are also excluded.

Given the distribution in Fig. 1b, we define deepening ETCs as the cyclones with deepening rates greater than $0.24 \mathrm{hPa} \mathrm{day}{ }^{-1}$, decaying ETCs as the cyclones with deepening rates less than $-0.24 \mathrm{hPa} \mathrm{day}^{-1}$, and neutral ETCs as the cyclones with deepening rates within $\pm 0.24 \mathrm{hPa}$ day $^{-1}$ and a negative second derivative (i.e., maxima in Fig. 1a). There are 28328 snapshots from 8486 deepening ETCs, 26431 snapshots from 8742 neutral ETCs, and 21929 snapshots from 7164 decaying ETCs. Collocation with MODIS overpasses samples only portions of these snapshots and further reduces the sample sizes to about 1000-2000 at

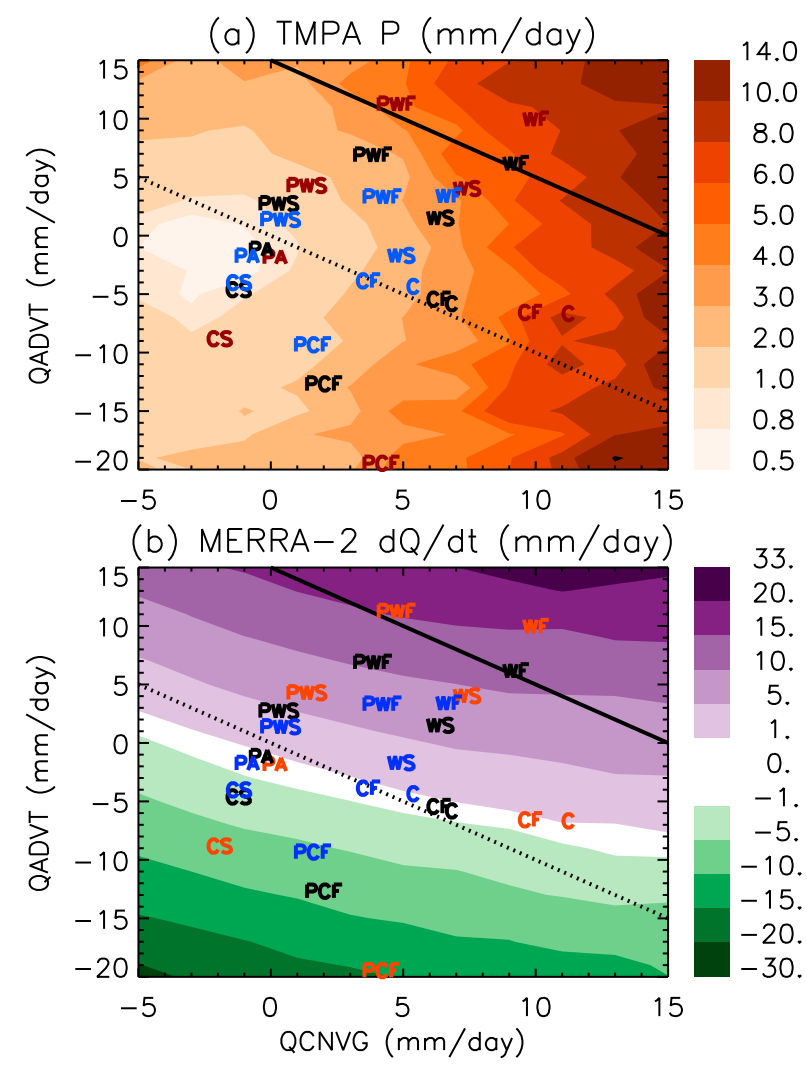

FIG. 3. (a) TMPA $P\left(\mathrm{~mm} \mathrm{day}^{-1}\right)$ and (b) MERRA-2 $\partial Q / \partial t$ ( $\mathrm{mm}^{-1}$ day) as functions of $Q_{\mathrm{cnvg}}\left(\mathrm{mm} \mathrm{day}^{-1}\right)$ and $Q_{\text {advt }}\left(\mathrm{mm}\right.$ day ${ }^{-1}$; see section $3 \mathrm{~d}$ for definitions of these two variables). The dotted lines indicate where moisture flux convergence $\left(Q_{\mathrm{cnvg}}+Q_{\mathrm{advt}}\right)$ is zero, and the solid lines indicate where $Q_{\mathrm{cnvg}}+Q_{\text {advt }}=$ a nonzero constant (here it is 15 as an example). The labels mark the coordinates that represent the average $Q_{\mathrm{cnvg}}$ and $Q_{\mathrm{advt}}$ in each sector (see Table 1) for each development stage of ETCs, with cyclones of Acc, Stn, and Dec stages marked in red, black, and blue labels, respectively.

the center and about 200 at about $1300 \mathrm{~km}$ from the center. ETC composites are constructed according to these three evolution stages in the ETC coordinate system described below.

\section{c. ETC coordinate}

To reveal the structures of either surface fronts (warm or cold), composites of cloud and dynamical fields are commonly constructed by rotating the targeted surface fronts into a fixed direction (Naud et al. 2010, 2012, 2016; Booth et al. 2013). As the relative locations of warm and cold fronts vary across cases, by fixing the direction of one front when compositing, the other front becomes smoothed, and its typical structure is lost in the average. In this study, we introduce an ETC coordinate in which the warm fronts are fixed in the direction of positive abscissa $\left(x_{\mathrm{ETC}}\right)$, and the cold fronts in the direction 
(a) Hgh Cld.: C

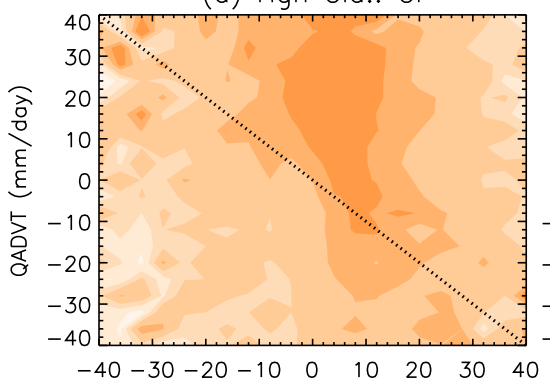

(b) Mid Cld.: Ac

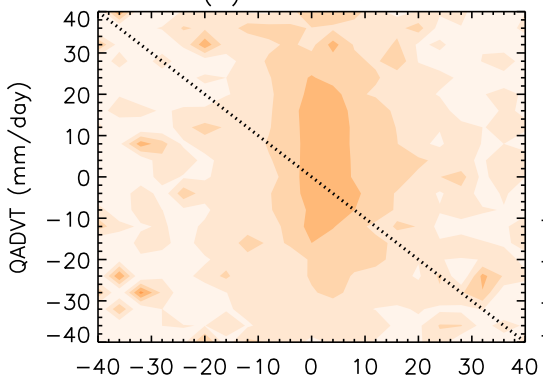

(c) Low Cld.: $\mathrm{Cu}$

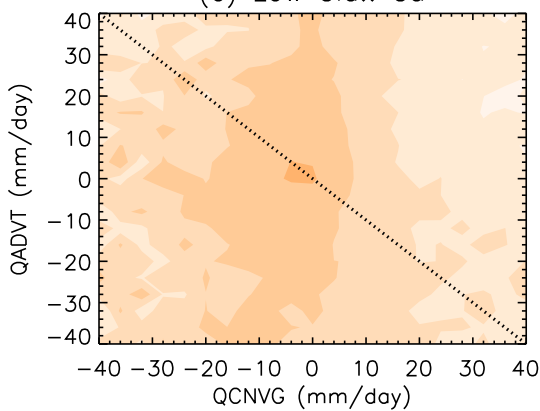

Cs

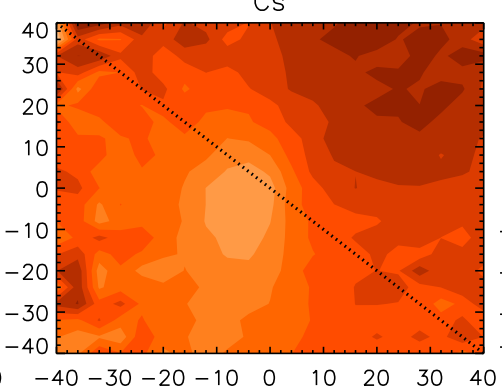

As

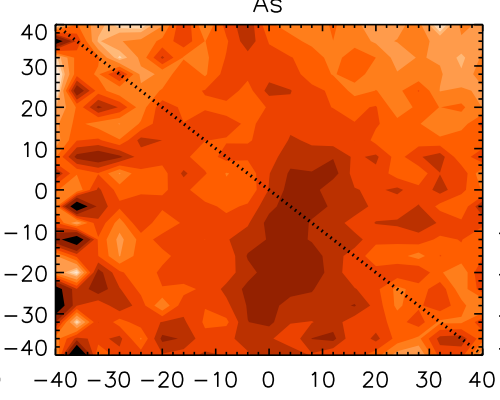

Sc

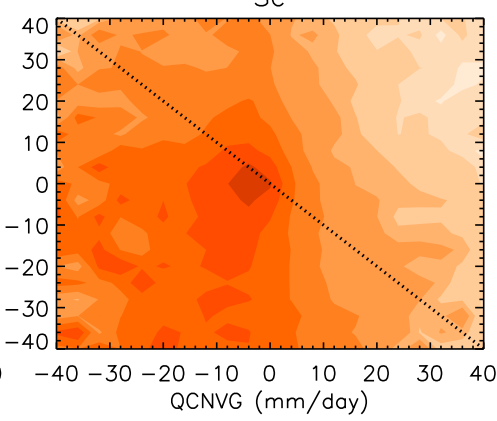

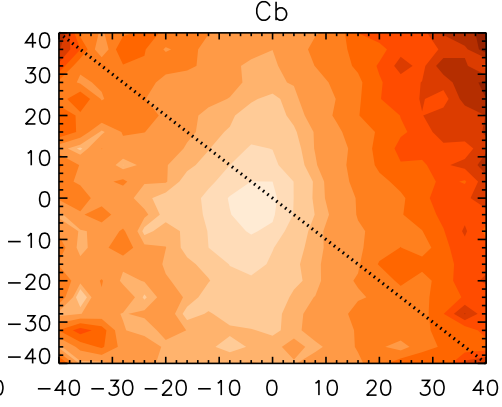
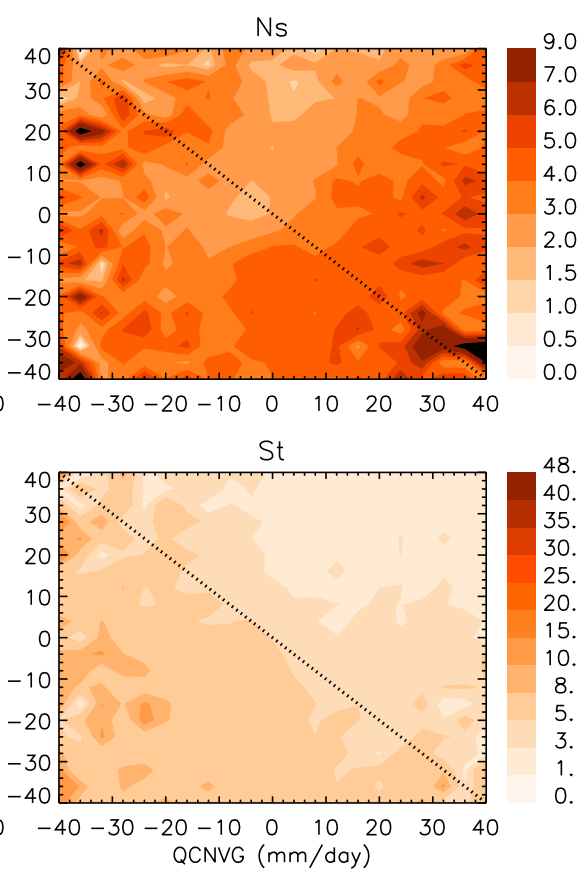

FIG. 4. Occurrence frequencies of nine cloud types as functions of $Q_{\mathrm{cnvg}}\left(\mathrm{mm} \mathrm{day}^{-1}\right)$ and $Q_{\text {advt }}\left(\mathrm{mm} \mathrm{day}^{-1}\right)$ for (a) high-level clouds Ci, $\mathrm{Cs}$, and $\mathrm{Cb}$; (b) mid-level clouds Ac, As, and Ns; and (c) low-level clouds, Cu, Sc, and St. The frequencies are counted with bin widths of $4 \mathrm{~mm} \mathrm{day}^{-1}$ in both $Q_{\mathrm{cnvg}}$ and $Q_{\text {advt }}$ and for all data within $1300 \mathrm{~km}$ from the centers of all ETC snapshots. The dotted lines indicate where moisture flux convergence $\left(Q_{\text {cnvg }}+Q_{\text {advt }}\right)$ is zero. Cloud-type definitions are according to Rossow and Schiffer (1999; see text section 2).

of negative ordinate $\left(y_{\mathrm{ETC}}\right)$. In the appendix, we describe in detail how the coordinate transformation is accomplished between the longitude-latitude coordinates and the ETC coordinates.

\section{d. Moisture flux convergence phase space}

Moisture flux convergence in the water vapor budget equation is separated into two terms (Wong et al. 2016):

$$
\begin{aligned}
P-E+\frac{\partial Q}{\partial t} & =-\nabla \cdot(Q \mathbf{V})=-\mathbf{V} \cdot \nabla Q-Q \nabla \cdot \mathbf{V} \\
& \equiv Q_{\mathrm{advt}}+Q_{\mathrm{cnvg}},
\end{aligned}
$$

with

$$
Q=\int_{p_{\text {top }}}^{p_{\text {sff }}} q \frac{d p}{g} \text { and } \mathbf{V}=\frac{1}{Q} \int_{p_{\text {top }}}^{p_{\text {sff }}} q \mathbf{v} \frac{d p}{g}
$$

where $Q$ is the column-integrated specific humidity $q$, and $\mathbf{V}$ is the vertically averaged horizontal wind $\mathbf{v}$ weighted by the vertical profile of specific humidity (or columnintegrated moisture flux divided by $Q$ ). Both $Q$ and $\mathbf{V}$ are obtained from MERRA-2 hourly column-integral data at $0.5^{\circ}$ latitude $\times 0.625^{\circ}$ longitude resolution. The term of moisture advection $-\mathbf{V} \cdot \nabla Q\left(Q_{\text {advt }}\right)$ and the term of moisture dynamical convergence $-Q \nabla \cdot \mathbf{V}\left(Q_{\text {cnvg }}\right)$ were used to construct a two-dimensional phase space (the $Q_{\mathrm{cnvg}}$ $Q_{\text {advt }}$ space) to quantify the relationship between clouds, precipitation, and the large-scale circulation (Wong et al. 2016); the coupling between phases of moisture flux convergence and transition of shallow-to-deep convection in the intraseasonal oscillation of the Indian summer monsoon (Wang et al. 2015; Wu et al. 2018); and the dependence of precipitation and surface evaporation on moisture flux convergence (Wong and Behrangi 2018). In 

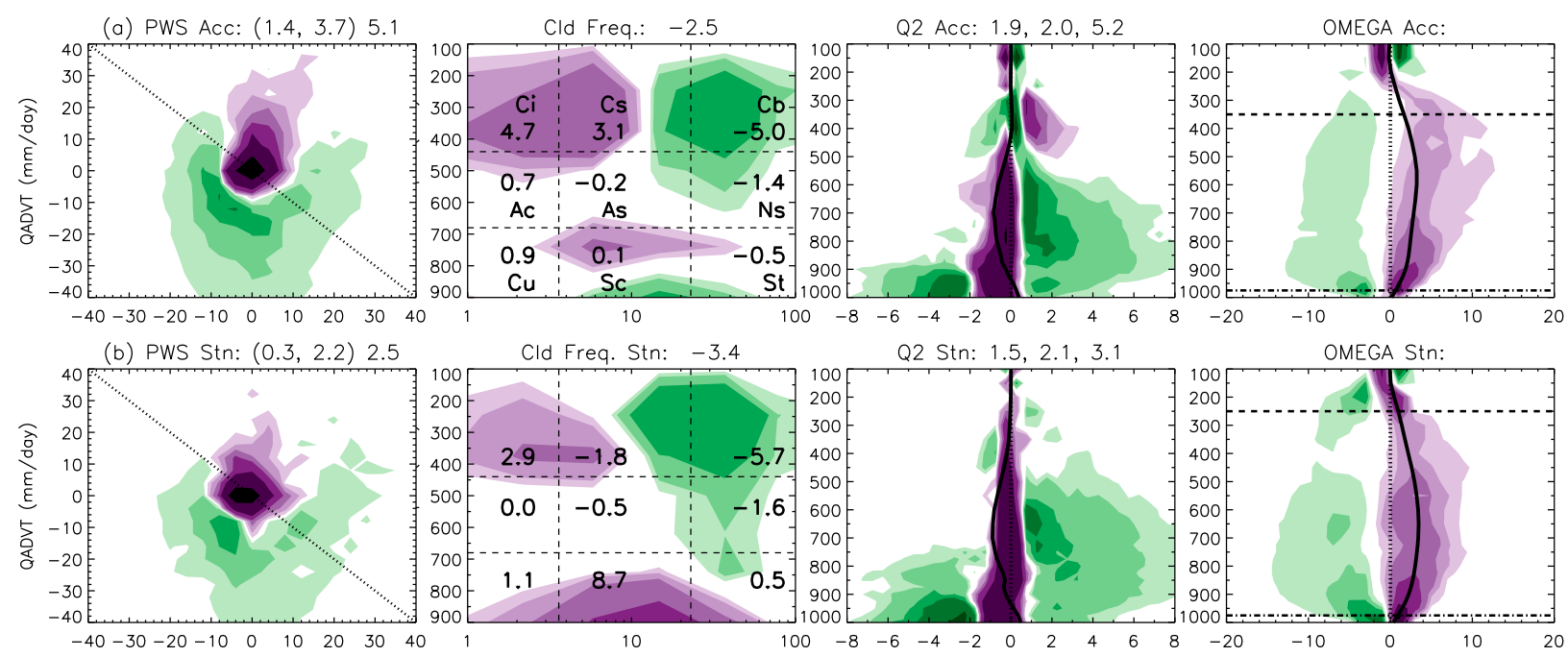

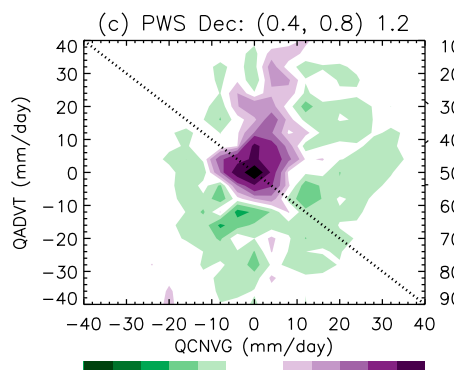

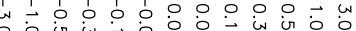

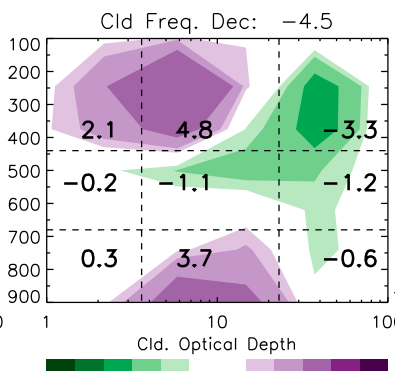

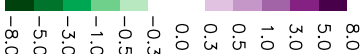

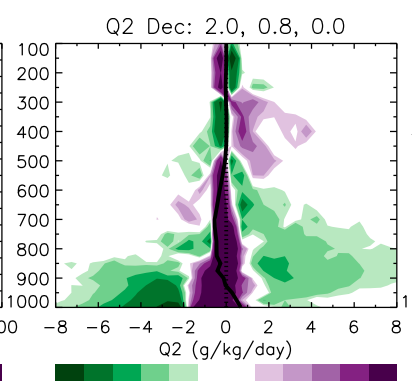

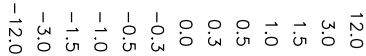

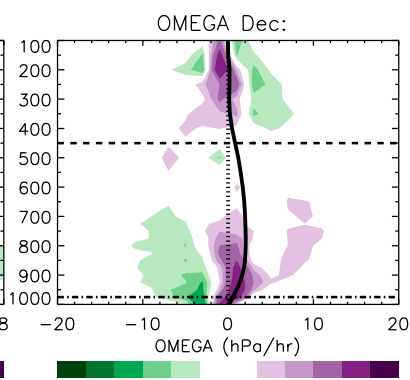

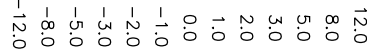

FIG. 5. For the PWS, histogram anomalies in (first column) $Q_{\text {advt }}$ vs $Q_{\text {cnvg }}$ (\%), (second column) CTP vs COD (\%), (third column) Q2 $(\%)$, and (fourth column) $\omega(\%)$ for cyclones of (a) deepening (Acc), (b) neutral (Stn), and (c) decaying (Dec) stages. The average $Q_{\text {cnvg }}$ and $Q_{\text {advt }}$ are listed in parentheses in the titles of the first column, and the numbers outside the parentheses are the average moisture flux convergence $\left(Q_{\text {cnvg }}+Q_{\text {advt }}\right)$. Numbers in the nine boxes in the second column are the occurrence frequency anomalies of the nine cloud types (see text for definitions). Labels of cloud types (see section 2) are included in the nine boxes in the top row of the second column for reference. The clear sky frequency anomalies are listed in the titles. The average $P$, surface evaporation rate, and $\partial Q / \partial t$ are listed in the third column titles, respectively. The solid lines in the third and fourth columns are the average Q2 and $\omega$ anomalies, respectively, with the horizontal dash and dash-dotted lines indicating the estimated average levels of convergence and divergence, respectively.

this study, we apply the $Q_{\text {cnvg }} Q_{\text {advt }}$ space to examine the phases of moisture flux convergence in each sector of ETCs during their life cycles. We note that $Q_{\text {cnvg }}$ and $Q_{\text {advt }}$ are derived from variables at the MERRA-2 horizontal resolution (referred to as "large scale" in this study) instead of fine resolution that can resolve mesoscale processes. Therefore, the connection between phases of moisture flux convergence and cloud properties, which are reported at $5-\mathrm{km}$ resolution, should be interpreted as the responses of the statistical distributions of mesoscale cloud properties (or cloud-type combinations) to moisture transport properties of the large-scale circulation.

\section{Characteristics of ETCs in the ETC coordinate and $Q_{\text {cnvg }} Q_{\text {advt }}$ phase space}

With both warm and cold fronts collocated across cyclones in the ETC coordinate, Fig. 2 shows composites of TMPA precipitation ( $P$; first column), MERRA-2 precipitable water vapor (PWV; second column), PWV tendency ( $\partial Q / \partial t$; third column), $Q_{\text {cnvg }}$ (fourth column), and $Q_{\text {advt }}$ (fifth column) for deepening (Acc), neutral (Stn), and decaying (Dec) cyclones. Since each grid cell in the ETC coordinate may contain samples with varying geographical gridcell area, area averages are performed for the composites. Sectors of ETCs are defined as regions that show consistent characteristics in composites of phases of moisture flux convergence, CTP versus COD histograms, and vertical velocity $\omega$ profiles. We name the different sectors as pre-warm sector (PWS), pre-warm front (PWF), surface warm front (WF), warm sector (WS), surface cold front (CF), postcold front (PCF), cold sector (CS), polar air intrusion (PA), and the center (C; see Fig. 2). Table 1 specifies the horizontal ranges of ETC coordinates for each sector definition. We acknowledge that these names can be 

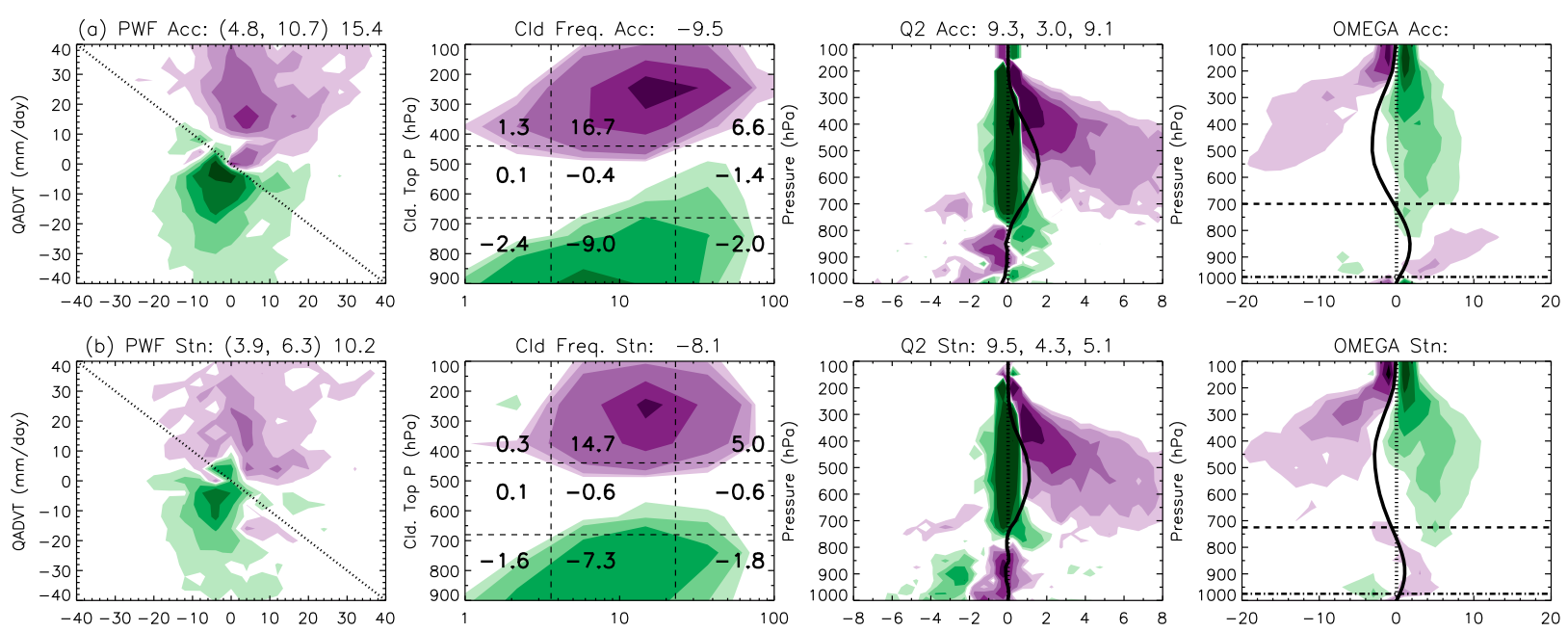

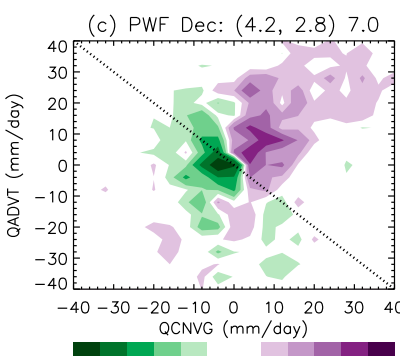

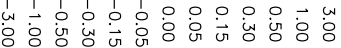

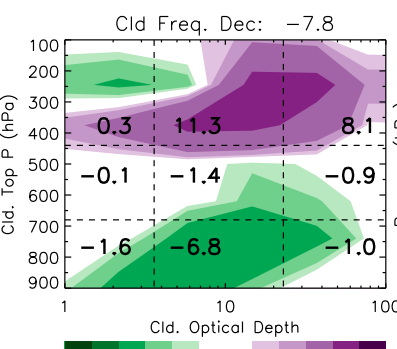

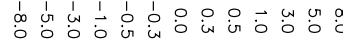

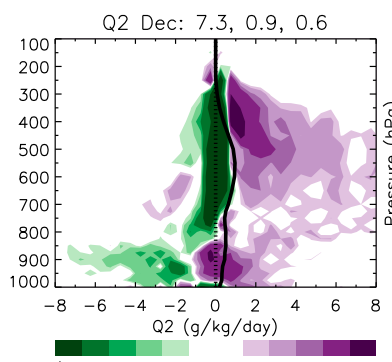

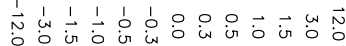

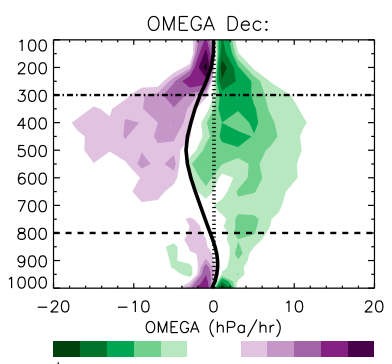

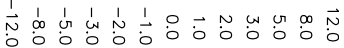

FIG. 6. As in Fig. 5, but for the PWF sector.

different from those conventionally used in the literature. For example, the sectors PCF, CS, and PA may be collectively named as the cold sector, and PWF and WF are not distinguished separately in other work.

During the deepening stage (Fig. 2, top row), rainbands are clearly concentrated along the WF and CF, with the WF rain distributed closer to the center than the CF. A band of maximum PWV [the atmospheric river (AR)] is located in the WS alongside the CF, consistent with the structures reported in Cordeira et al. (2013) and Dacre et al. (2015), and the driest and coldest air is in the PA. The atmosphere is moistened $(\partial Q / \partial t>0)$ in the quadrants of $x_{\mathrm{ETC}}>0$ and dried $(\partial Q / \partial t<0)$ in the quadrants of $x_{\mathrm{ETC}}<0$ (except in the CF). Positive tendencies in the upper-right quadrant (PWS) are mainly caused by moisture advection. Rain bands associated with both fronts are positioned in narrow areas with large gradients of PWV, with the WF located within the region of both maximum $Q_{\text {cnvg }}$ and $Q_{\text {advt }}$, and the CF nearest to the region of maximum convective available potential energy (CAPE; not shown, but similar to the distribution of PWV).

The PWV in the WS is largest during the neutral stage (Fig. 2, middle row). Patterns of $\partial Q / \partial t, Q_{\mathrm{cnvg}}$, and $Q_{\text {advt }}$ in the neutral stage are similar to those in the deepening stage, but with smaller magnitudes accompanying the lighter precipitation. The rain rate in the CF becomes much weaker than that in the WF.

During the decaying stage (Fig. 2, bottom row), precipitation within ETCs is the lightest among the evolution stages. While the WF rainband is still apparent, the CF rainband becomes indistinguishable from the WS precipitation. Moreover, the AR also becomes less distinguishable, with negative values of $\partial Q / \partial t$ and $Q_{\text {advt }}$ beginning to appear in the WS. The decaying stage contains the most frequent occluded fronts. In such cases, the front location algorithm still detects a surface front but tends to flag it as a WF. It is likely that this results in the less distinguishable structure observed in the $\mathrm{CF}$ and WS during the decaying stage. Identifying occluded fronts and properly accounting for them in a transformed coordinate system warrant further investigation in future work.

Composites of $P$ and $\partial Q / \partial t$ on the $Q_{\mathrm{cnvg}} Q_{\text {advt }}$ space are shown in Fig. 3. Data are binned in the phase space with bin widths of $4 \mathrm{~mm} \mathrm{day}^{-1}$. Contours of constant $P$ (Fig. 3a) align more along the $Q_{\text {advt }}$ axis when $Q_{\text {cnvg }}>0$, indicating that $P$ is more sensitive to $Q_{\text {cnvg }}$ (and the 

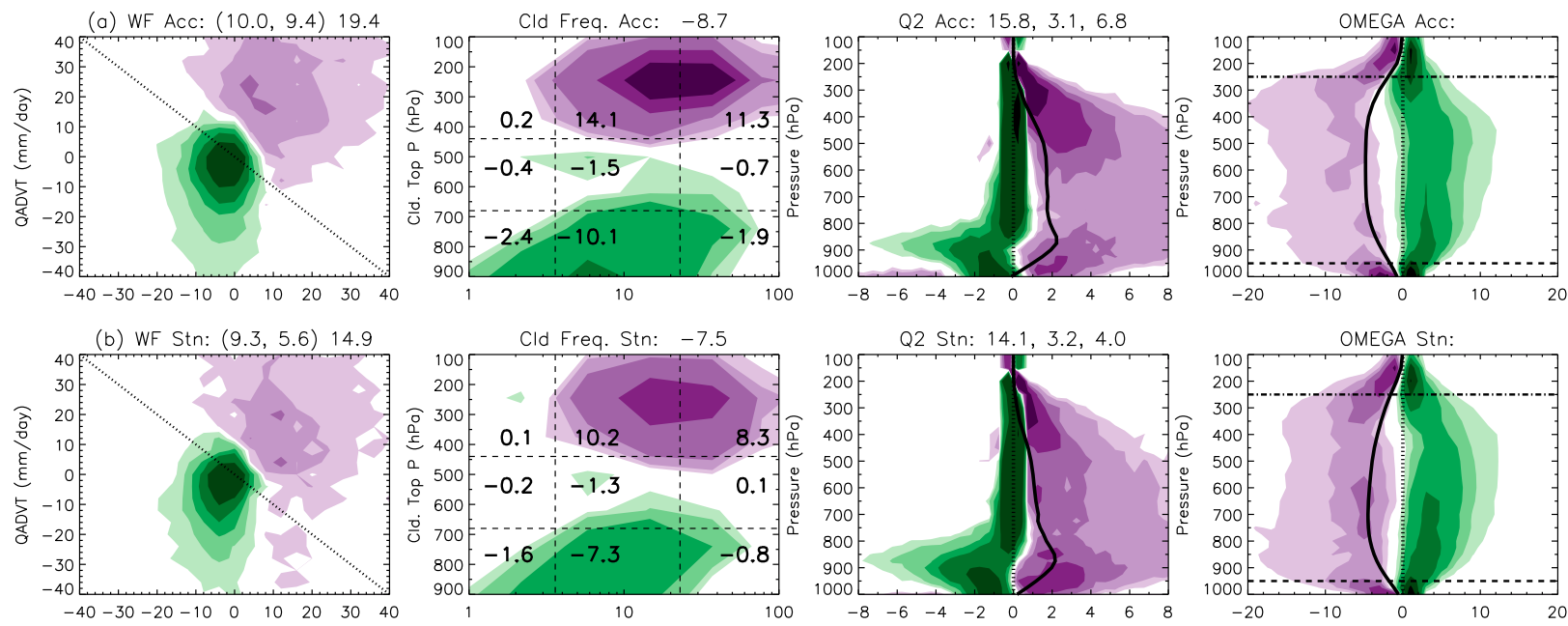

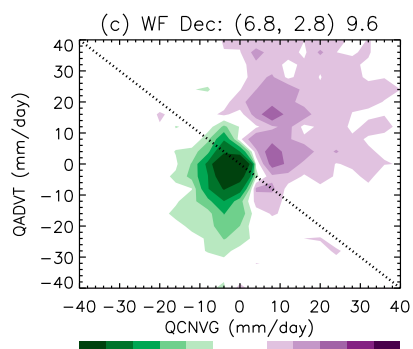

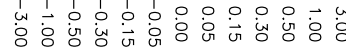

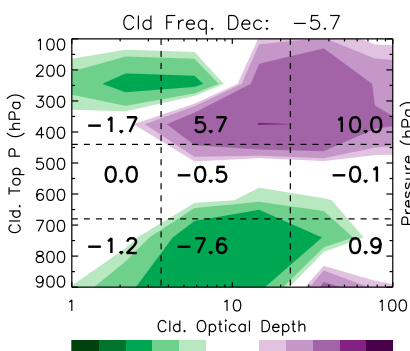

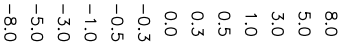
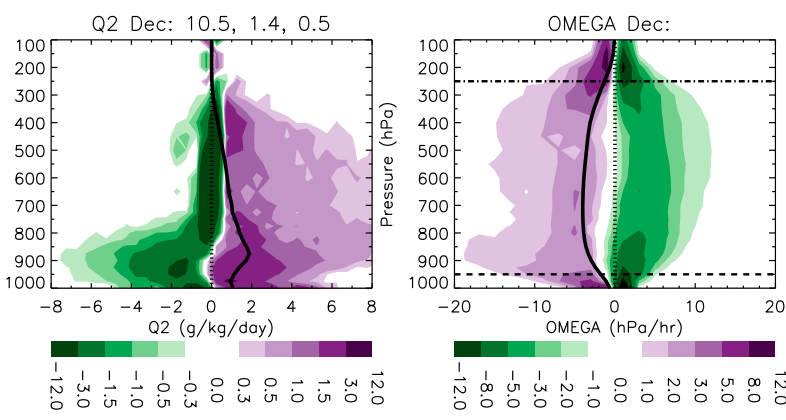

FIG. 7. As in Fig. 5, but for the WF sector.

associated uplift) than to $Q_{\text {advt }}$. In contrast, $\partial Q / \partial t$ (Fig. 3b) is more sensitive to $Q_{\text {advt }}$ than to $Q_{\text {cnvg. }}$.

Lines of constant moisture flux convergence $\left(Q_{\mathrm{advt}}+\right.$ $Q_{\text {cnvg }}=$ const.) align parallel to the dotted line (the line of zero moisture flux convergence; $Q_{\mathrm{advt}}+Q_{\mathrm{cnvg}}=0$ ). Along a line of constant positive value of $Q_{\text {advt }}+Q_{\text {cnvg }}$ (the solid lines in Fig. 3), larger positive $Q_{\text {advt }}$ corresponds to larger $\partial Q / \partial t$ and smaller $P$, implying that the supply of moisture favors moistening the atmosphere rather than precipitation. Along the same line, larger positive $Q_{\text {cnvg }}$ implies that the supply of moisture favors precipitation. Since changing PWV and precipitation formation are related to the cloud types in the atmosphere, there are variable combinations of cloud types along a line of constant $Q_{\mathrm{advt}}+Q_{\mathrm{cnvg}}$ because of the relative contributions of $Q_{\text {advt }}$ and $Q_{\text {cnvg. }}$.

The occurrence frequencies of each of the nine cloud types as functions of $Q_{\mathrm{advt}}$ and $Q_{\mathrm{cnvg}}$ are shown in Fig. 4. The frequencies are counted by clouds that are detected by MODIS within $1300 \mathrm{~km}$ from the centers of collocated ETC snapshots. The sum of all nine panels in Fig. 4 plus the clear one (not shown) is $100 \%$ for all $Q_{\text {advt }}$ and $Q_{\text {cnvg. }}$. Different regimes in the $Q_{\text {cnvg }} Q_{\text {advt }}$ phase space are in favor of different combinations of cloud types. For example, $\mathrm{Ci}$ and Ac mainly occur in conditions with large positive $Q_{\text {advt }}$ but relatively small positive $Q_{\mathrm{cnvg}}$, while As and Sc mainly occur in conditions with negatively large $Q_{\text {advt }}$. Both Cs and $\mathrm{Cb}$ are most likely in a regime when both $Q_{\mathrm{advt}}$ and $Q_{\mathrm{cnvg}}$ are large and positive. However, the occurrence frequencies of $\mathrm{Cb}$ are distributed similarly to that of precipitation (Fig. 3a), sensitive to changes in $Q_{\text {cnvg }}$ when $Q_{\text {cnvg }}>0$, while the frequencies of Cs have sharp gradients in the $Q_{\text {cnvg }}$ direction when $Q_{\text {cnvg }}$ approaches 0 and in the $Q_{\text {advt }}$ direction when $Q_{\text {advt }}$ approaches 0 . Although formation of $\mathrm{Cu}$ clouds need mesoscale convergence, it is linked to a regime of $Q_{\text {cnvg }}<0$ when large-scale variables are used to compute moisture budget terms.

\section{Precipitation, cloud structures, and moisture flux convergence in ETC sectors}

For each stage of cyclone evolution, we construct the histogram anomalies of $Q_{\text {advt }}$ versus $Q_{\text {cnvg }}$, CTP versus $\mathrm{COD}$, the apparent water vapor sink $(\mathrm{Q} 2)$ profiles, and the vertical wind speed profiles $\omega$ (as change rate of parcel pressure) for each sector of the ETCs (Figs. 5-13). Values of Q2 are computed using the MERRA-2 specific 

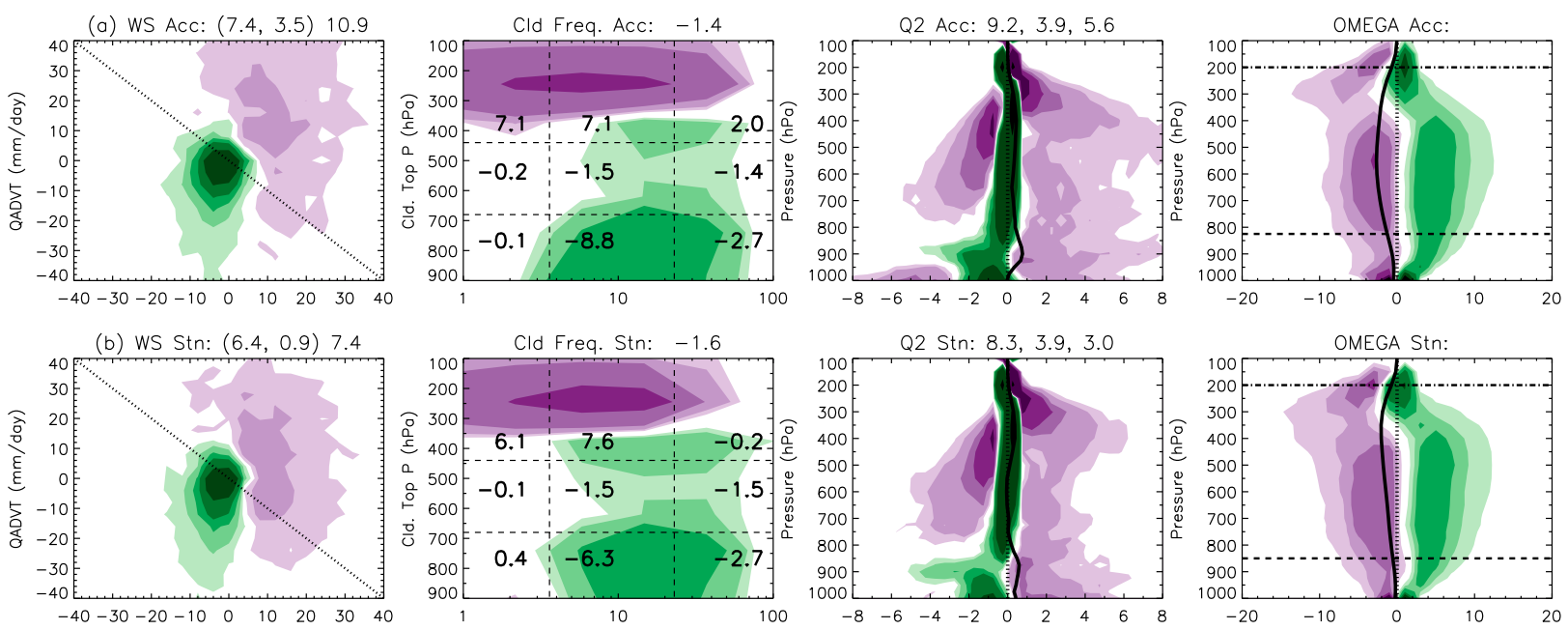

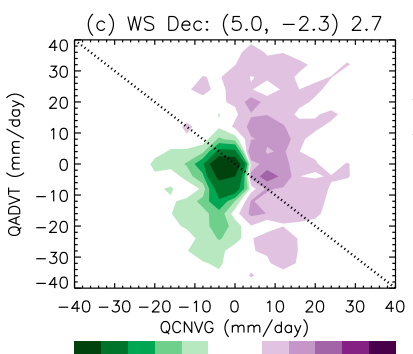

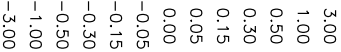

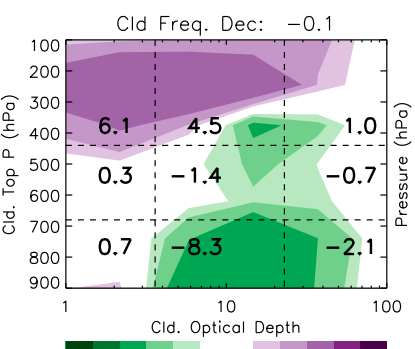

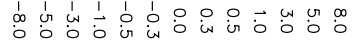

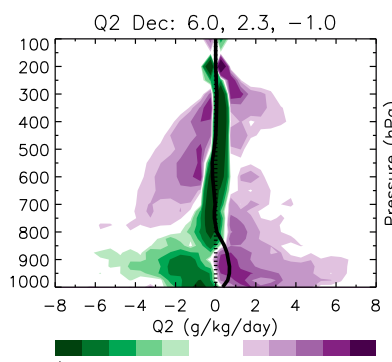

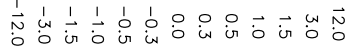

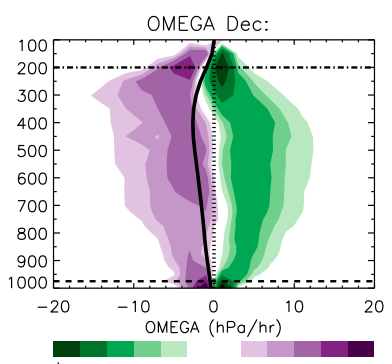

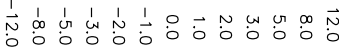

FIG. 8. As in Fig. 5, but for the WS.

humidity and wind velocities as in Wong et al. (2011a,b), with positive (negative) values indicating a loss (gain) of water vapor through condensation (evaporation) or subgrid-scale turbulent flux divergence (convergence). The histogram anomalies are computed as the histograms sampled only in one sector and one development stage minus the histograms sampled from all sectors and stages (i.e., sampled within $1300 \mathrm{~km}$ from the centers of all available ETC snapshots, referred to as the climatological histograms). As composites involve ETCs of various geometrical sizes, properties of the atmosphere outside small ETCs are also included. The anomalies highlight special features in one sector and stage relative to the climatologically average ETC properties. The histogram anomalies of $Q_{\text {advt }}$ versus $Q_{\text {cnvg }}$ and CTP versus COD are summed to zero for the individual histograms. The histogram anomalies of Q2 and $\omega$ profiles are summed to zero on each pressure level. The climatological histograms from which the anomalies deviate are shown in the appendix (Fig. A3).

\section{a. Pre-warm sector}

The PWS is located downwind of the WF and the moisture flux convergence (Fig. 5, first column) is primarily advective, with nearly zero average $Q_{\text {cnvg }}$ $\left(\sim 0.4-1.4 \mathrm{~mm} \mathrm{day}^{-1}\right)$ across the cyclone life cycle and a much larger positive average $Q_{\text {advt }}\left(\sim 0.8-3.7 \mathrm{~mm} \mathrm{day}^{-1}\right)$. The anomalous distribution in the $Q_{\text {cnvg }} Q_{\text {advt }}$ space shows large negative anomalies (green color) for regimes of dry advection, indicating redistribution of samples toward regimes of moist advection (purple color for $Q_{\text {advt }}>0$ ). Compared to the average $Q_{\text {cnvg }}$ of all sectors $\left(\sim 2.9 \mathrm{~mm} \mathrm{day}^{-1}\right.$ in Fig. A3), the PWS is less convergent. This is consistent with the larger proportion of descending (positive anomaly in positive $\omega$ in Fig. 5, fourth column) motions than ascending (negative $\omega$ ) motions. More $\mathrm{Ci}$ and $\mathrm{Cs}$ clouds accompany low-level clouds in this sector (Fig. 5, second column). The average precipitation rate (Fig. 5, third column; $1.5-2 \mathrm{~mm} \mathrm{day}^{-1}$ ) is small compared to that of all sectors $\left(6.2 \mathrm{~mm} \mathrm{day}^{-1}\right.$ in Fig. A3), while the atmosphere begins to store moisture (averaged $\partial Q / \partial t \sim 0-5.2 \mathrm{~mm} \mathrm{day}^{-1}$ ) relative to the average drying of all sectors $\left(\sim-2 \mathrm{~mm} \mathrm{day}^{-1}\right.$ in Fig. A3). This is consistent with Fig. 3 that the regime of large $Q_{\text {advt }}$ but relatively small $Q_{\text {cnvg }}$ has larger $\partial Q / \partial t$ than $P$. Positive anomalies in negative Q2 in the mid- to lower troposphere (Fig. 5, third column) indicate moistening, while positive anomalies in positive Q2 above $500 \mathrm{hPa}$ indicate the loss of water vapor to maintain high-level clouds detrained from the convection in the WF. Cyclone evolution 

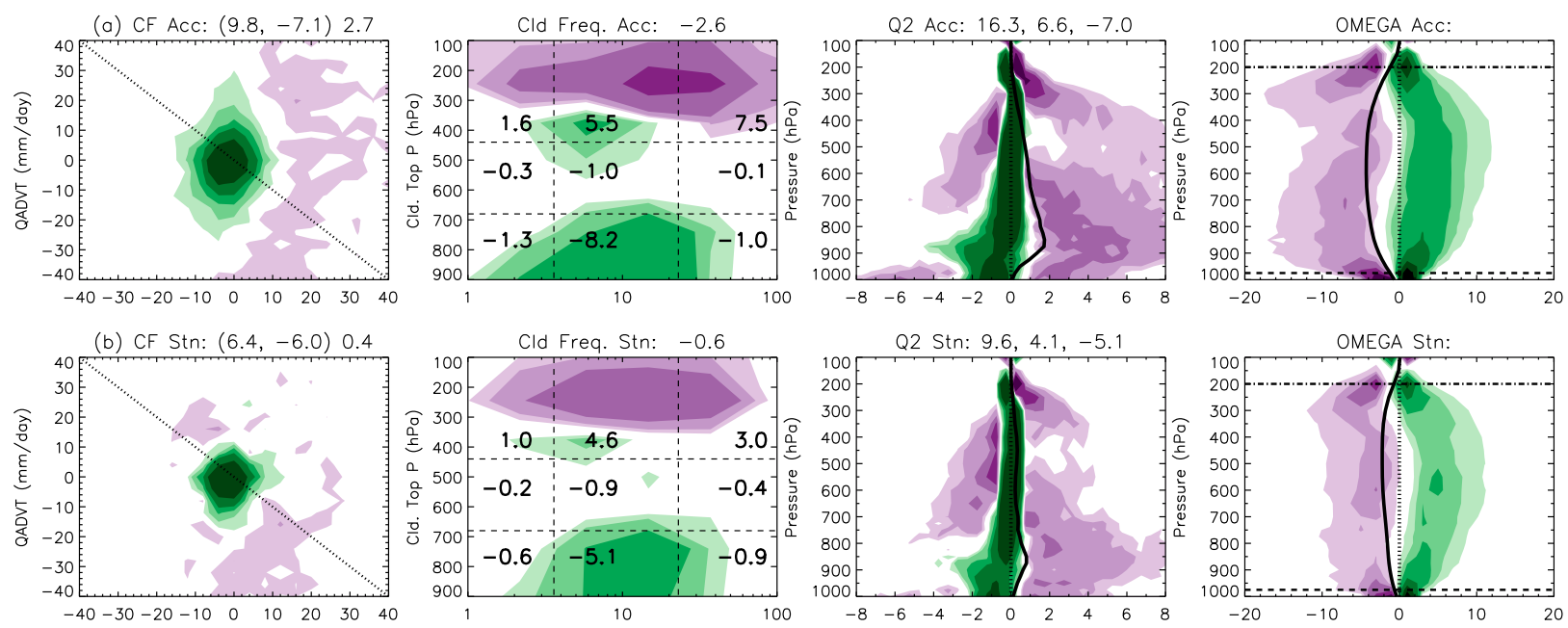

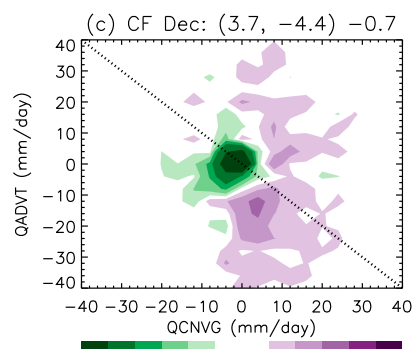

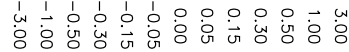

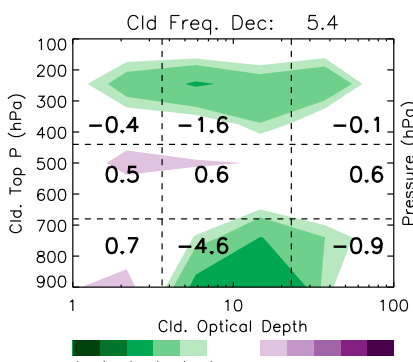

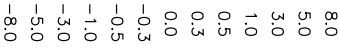
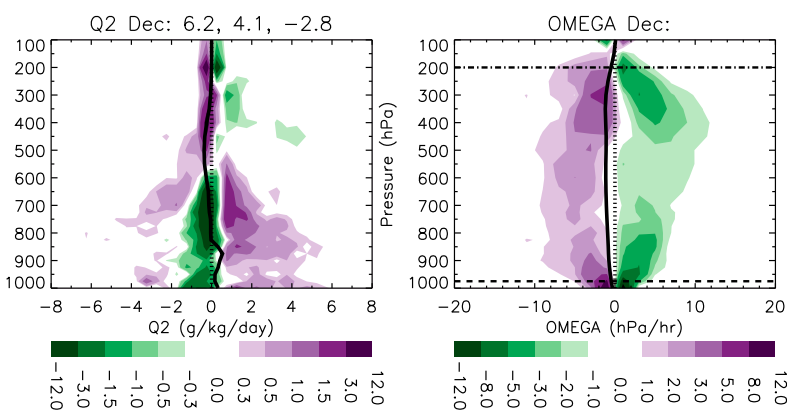

FIG. 9. As in Fig. 5, but for the CF sector.

only slightly modulates the characteristics of moisture flux convergence and clouds in the PWS. The average $Q_{\text {advt }}$ (Fig. 5, first column) decreases from the deepening to decaying stages with decreasing average $\partial Q / \partial t$ (Fig. 5, third column), consistent with Fig. 3b.

\section{b. Pre-warm front}

The PWF sector is located downwind of the WF where elevated ascending motion becomes evident. Both $Q_{\text {cnvg }}$ and $Q_{\text {advt }}$ are enhanced in the PWF (Fig. 6, first column) from the values in the PWS, resulting in a larger moisture flux convergence $\left(Q_{\mathrm{cnvg}}+Q_{\mathrm{advt}} \sim 7-15.4 \mathrm{~mm}_{\text {day }^{-1}}\right)$ compared to the PWS $\left(\sim 1.2-5.1 \mathrm{~mm} \mathrm{day}^{-1} ;\right.$ Fig. 5 , first column). The larger $Q_{\text {cnvg }}\left(\sim 3.9-4.8 \mathrm{~mm} \mathrm{day}^{-1}\right)$ compared to the climatological average $\left(2.9 \mathrm{~mm} \mathrm{day}^{-1}\right.$ in Fig. A3) is associated with the more frequent ascending motions (Fig. 6, fourth column) that are elevated, with ascent above $700-800 \mathrm{hPa}$ and descent below. This is consistent with the elevated ascent in the tilting portion ahead of surface warm fronts reported in Naud et al. (2010) and Booth et al. (2013). Compared to the PWS, the ascending motions are associated with more frequent occurrences of $\mathrm{Cs}$ to $\mathrm{Cb}$ clouds (Fig. 6, second column) and positive Q2 above $700-800 \mathrm{hPa}$ (Fig. 6, third column). Precipitation rates $\left(7.3-9.5 \mathrm{~mm} \mathrm{day}^{-1}\right.$ ) in the PWF sector are slightly above the climatological average rate $\left(\sim 6.3 \mathrm{~mm} \mathrm{day}^{-1}\right)$, and the average values of $\partial Q / \partial t$ are the highest among all sectors $(0.6-$ $9 \mathrm{~mm} \mathrm{day}^{-1}$ ).

From deepening to decaying stages, the average $Q_{\mathrm{cnvg}}$ does not change much, but the average $Q_{\text {advt }}$ significantly decreases by about 4 times (Fig. 6, first column). This development is shown as the labels of PWF in Fig. 3, which mark the average $Q_{\text {cnvg }}$ and $Q_{\text {advt }}$ as coordinates in the $Q_{\mathrm{cnvg}} Q_{\mathrm{advt}}$ space. From the deepening (the red PWF label) to the decaying stages (the blue PWF label), $\partial Q / \partial t$ undergoes a larger decrease than $P$ does, consistent qualitatively with the third column of Fig. 6, in which the average $P$ decreases from about 9 to $7 \mathrm{~mm} \mathrm{day}^{-1}$, but the average $\partial Q / \partial t$ decreases by an order of magnitude. We note that the values of $P$ and $\partial Q / \partial t$ shown in Fig. 3 are averages of all samples regardless of sectors or development stages, while the values shown in the third columns of Figs. 5-13 are averages in particular sectors at certain development stages and are different from those in Fig. 3. We will address the relationship between these two values in section 6 .

The path of the PWF labels in the $Q_{\text {cnvg }} Q_{\text {advt }}$ space indicates a tendency in Fig. 4a that the corresponding decrease in the frequency of $\mathrm{Cs}$ is larger than that of $\mathrm{Cb}$. 

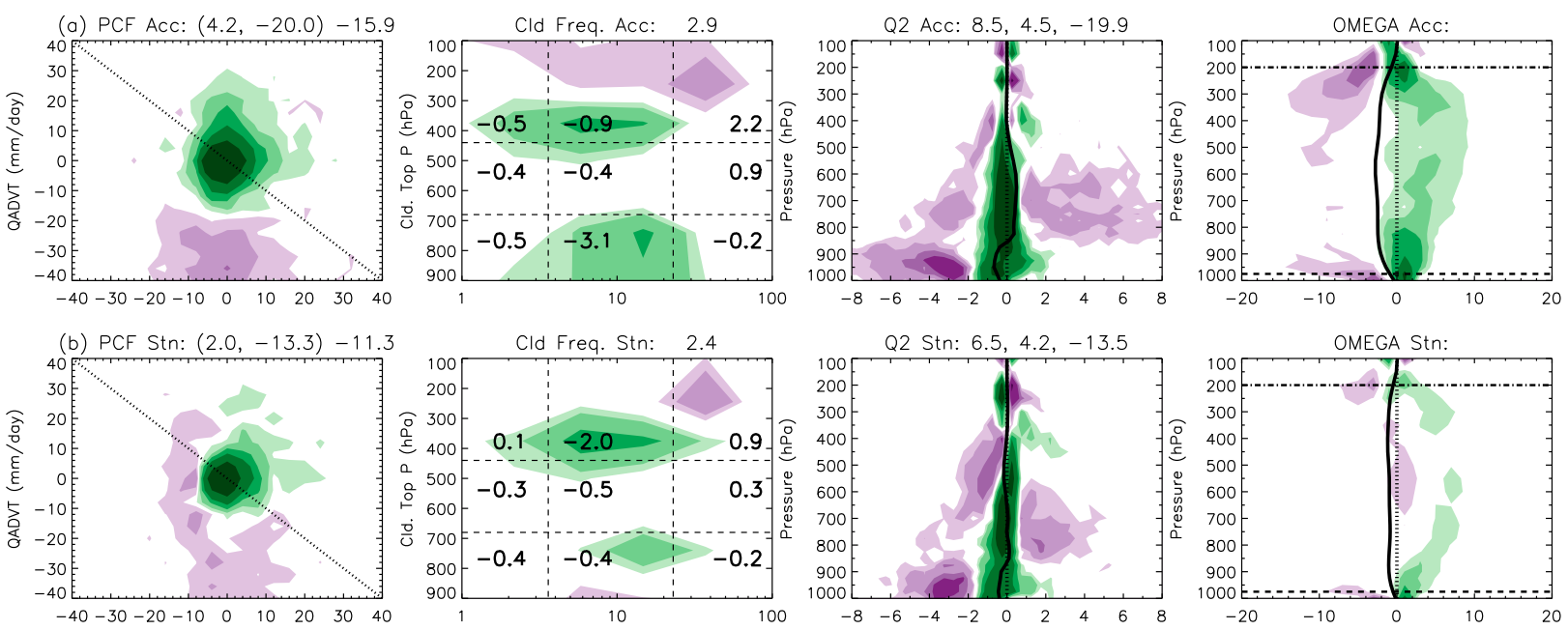

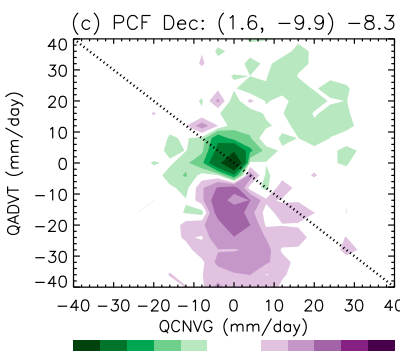

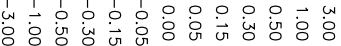

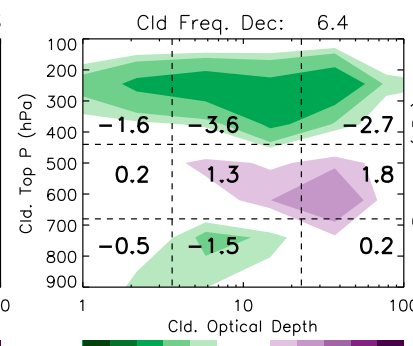

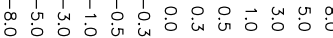

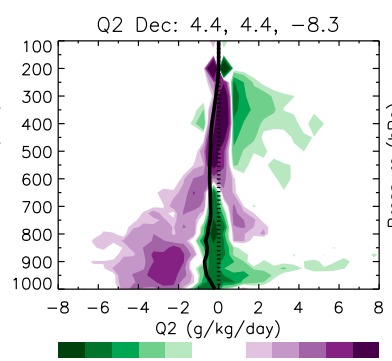

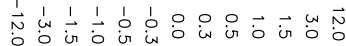

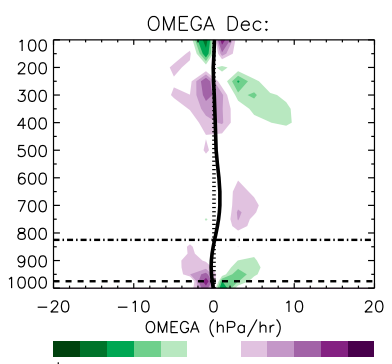

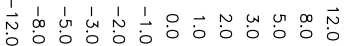

FIG. 10. As in Fig. 5, but for the PCF sector.

This is reflected in the second column of Fig. 6 such that the distribution of high-level clouds is more weighted toward $\mathrm{Cs}$ during the deepening stage and toward $\mathrm{Cb}$ during the decaying stage.

\section{c. Surface warm front}

With the average $Q_{\text {cnvg }}$ in the WF $\left(\sim 7-10 \mathrm{~mm} \mathrm{day}^{-1}\right.$; Fig. 7, first column) doubling those in the PWF, the upward motions become upright throughout the troposphere (Fig. 7, fourth column) with more frequent occurrence of $\mathrm{Cb}$ clouds (Fig. 7, second column) and the strongest precipitation rates $\left(10-16 \mathrm{~mm} \mathrm{day}^{-1}\right.$; Fig. 7 , third column). The moisture flux convergence in the WF is the largest among all sectors $\left(Q_{\mathrm{cnvg}}+Q_{\mathrm{advt}} \sim 10\right.$ $19 \mathrm{~mm}$ day $^{-1}$; Fig. 7, first column).

The modulation by cyclone life cycle is similar to that in the PWF sector. With $Q_{\text {advt }}$ decreasing more rapidly than $Q_{\text {cnvg }}$ (Fig. 7, first column) from the deepening to decaying stages, $\partial Q / \partial t$ decreases by one order of magnitude, while $P$ decreases by just about one-third (Fig. 7, third column). These changes are accompanied by a large decrease in the occurrence frequency of Cs and a steady occurrence frequency of $\mathrm{Cb}$, with the high-level clouds weighted more toward $\mathrm{Cb}$ (Fig. 7, second column) in the decaying stage. This phenomenon was observed in the case study of a stationary WCB by Crespo and Posselt (2016).

\section{d. Warm sector}

The WS is located upwind of the WF, with the most abundant PWV (Fig. 2, second column) being transported in the AR. Both the average $Q_{\mathrm{cnvg}}$ and $Q_{\mathrm{advt}}$ decrease in the WS (Fig. 8, first column) from the values in the WF sector (Fig. 7, first column), accompanied with smaller average $P$ and $\partial Q / \partial t$ (Fig. 8, third column) compared to the WF sector. Upward vertical velocities (Fig. 8, fourth column) are weaker than those in the WF sector, and the occurrence frequencies of $\mathrm{Cs}$ and $\mathrm{Cb}$ (Fig. 8, second column) are reduced from the WF sector. Ci clouds are more abundant (Fig. 8, second column). Negative Q2 in the 300-700-hPa layer (Fig. 8, third column) indicates the evaporation of stratiform precipitation, and positive Q2 in the 200-300-hPa layer (about the same levels of mass divergence; dash-dotted lines in Fig. 8, fourth column) helps maintain the existence of high-level stratiform clouds.

From the deepening to decaying stages, there are larger decreases in the average $Q_{\mathrm{advt}}$ than decreases in the average $Q_{\text {cnvg }}$ (Fig. 8, first column). Similar to the PWF and WF sectors, average $\partial Q / \partial t$ in the WS decreases more than 

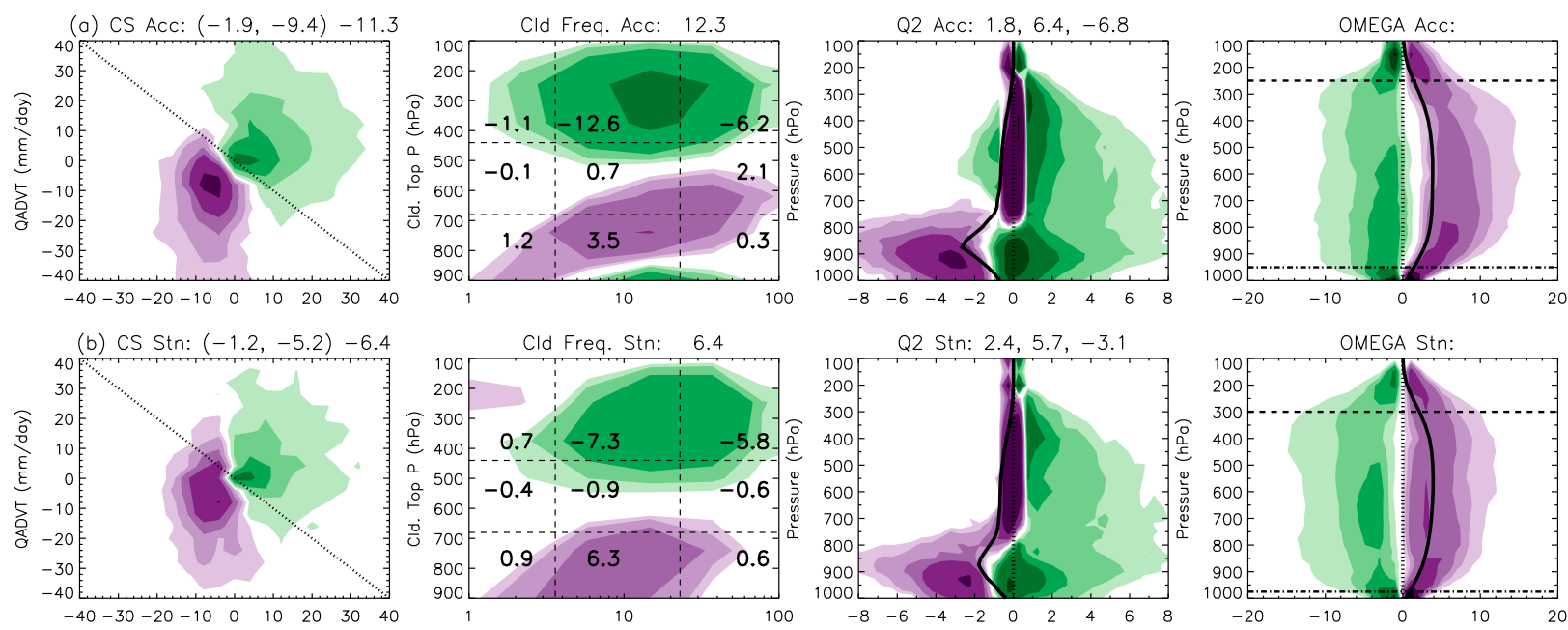

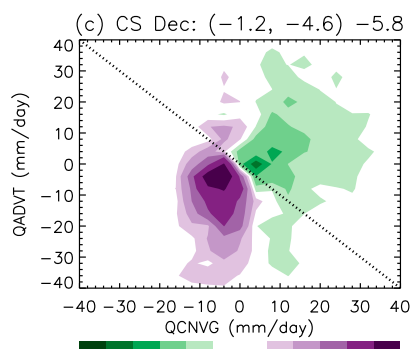

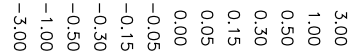

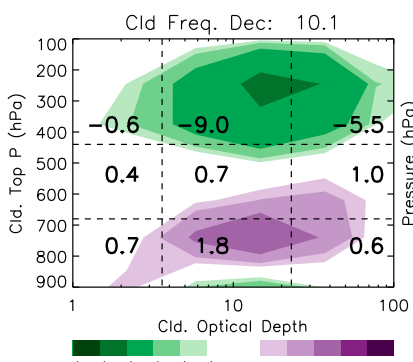

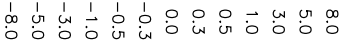
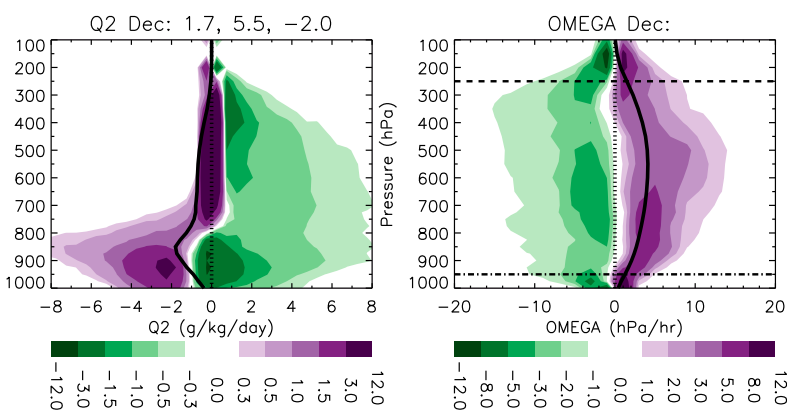

FIG. 11. As in Fig. 5, but for the CS.

the average $P$ (Fig. 8, third column), consistent with Fig. 3 . This is accompanied by a decrease in the occurrence frequencies of Cs with a fairly steady occurrence frequency of $\mathrm{Ci}$ (Fig. 8, second column). The path of the development of WS in the $Q_{\text {cnvg }} Q_{\text {advt }}$ space (the WS labels in Fig. 3) is in a regime of a large gradient of Cs occurrence frequency, but steady maximum of $\mathrm{Ci}$ occurrence frequency (Fig. 4a).

\section{e. Surface cold front}

Phases of moisture flux convergence in the $\mathrm{CF}$ sector exhibit a wide extent across the $Q_{\text {advt }}$ direction in the $Q_{\text {cnvg }} Q_{\text {advt }}$ space (Fig. 9, first column). This is because of the sharp gradient of $Q_{\text {advt }}$ across the CF, from a positive value in the WS transitioning to a negative value in the PCF. The characteristics of moisture flux convergence and cloud-type combinations in the CF are significantly modulated by cyclone life cycle (see Fig. 9).

In the deepening stage, positive average $Q_{\text {cnvg }}$ $\left(\sim 10 \mathrm{~mm} \mathrm{day}^{-1}\right.$; Fig. 9a, first column $)$ is associated with more upright ascending motions (Fig. 9a, fourth column $)$ and average precipitation $\left(\sim 16 \mathrm{~mm} \mathrm{day}^{-1}\right.$; Fig. 9a, third column) that are as strong as those in the WF (Fig. 7a, fourth column). The water budget and the cloudtype combinations are different from those in the WF. As the average $Q_{\text {cnvg }}$ is about equal in the $\mathrm{CF}$ and $\mathrm{WF}$ $\left(\sim 10 \mathrm{~mm} \mathrm{day}^{-1}\right)$, the $\mathrm{CF}$ is subject to a large negative average $Q_{\text {advt }}\left(\sim-7 \mathrm{~mm} \mathrm{day}^{-1}\right)$, resulting in a much smaller average moisture flux convergence $\left(2.7 \mathrm{~mm} \mathrm{day}^{-1}\right)$ compared to the WF value $\left(19.4 \mathrm{~mm} \mathrm{day}^{-1}\right)$. To support the high average precipitation rates, the water vapor converted to precipitation comes from the AR with large negative $\partial Q / \partial t\left(\sim-7 \mathrm{~mm}\right.$ day $^{-1}$; Fig. 9a, third column $)$ and from surface evaporation $\left(\sim 6.6 \mathrm{~mm} \mathrm{day}^{-1}\right)$, which is twice of that in the WF $\left(3.1 \mathrm{~mm} \mathrm{day}^{-1}\right)$. Consequently, among sectors where the average precipitation rates are high, the CF in a deepening ETC is where strong interactions occur with the ocean surface.

Occurrence frequencies of high-level clouds in the CF of deepening ETCs are distributed with more weight toward Cb (Fig. 9a, second column), consistent with the observation of more isolated deep convective clouds in the CF (Houze and Hobbs 1982; Crespo and Posselt 2016). The mid- to low-tropospheric positive Q2 (600$1000 \mathrm{hPa}$ in Fig. 9a, third column) are typically associated with $\mathrm{Cb}$. The long tail in the high-level cloud frequency distribution extends across Cs and Ci regimes, accompanied by the upper-tropospheric positive Q2 (150-300 hPa in Fig. 9a, third column) and midtropospheric negative Q2 $(300-700 \mathrm{hPa}$ in Fig. 9a, third 

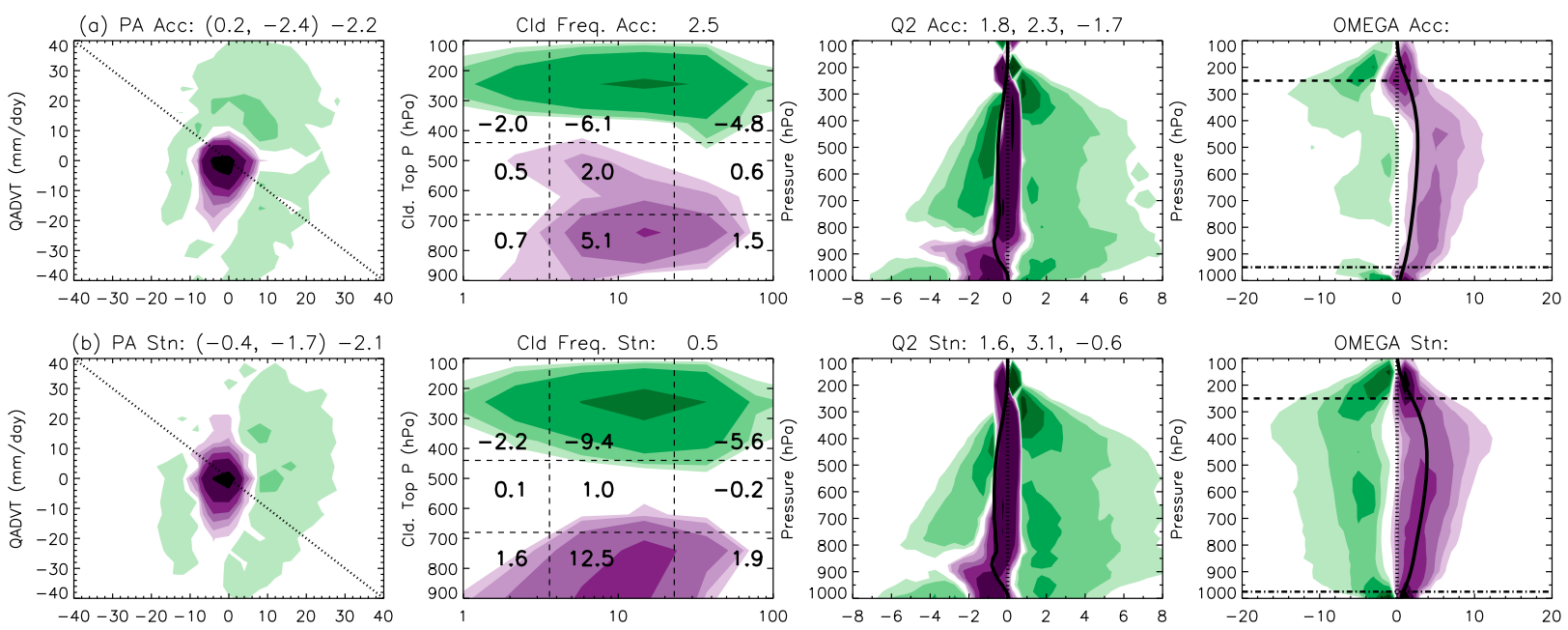

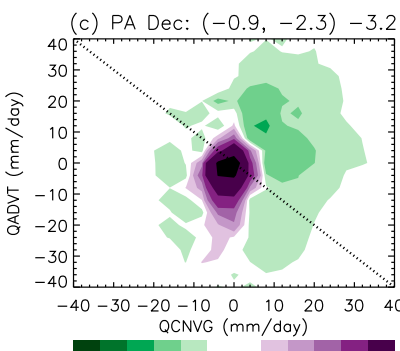

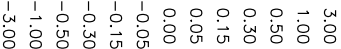
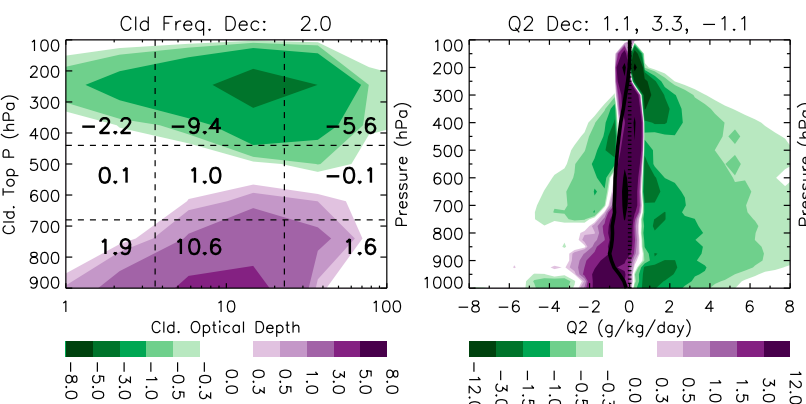

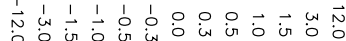

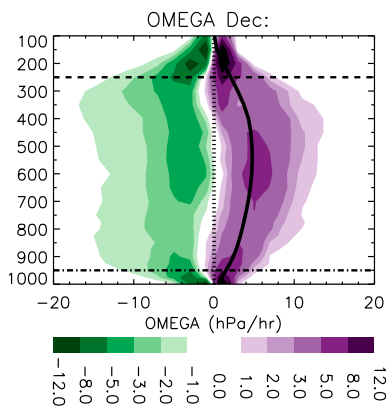

FIG. 12. As in Fig. 5, but for the PA sector.

column). These are related to the maintenance of highlevel stratiform clouds and evaporation of stratiform precipitation, respectively.

In the neutral stage, $\mathrm{Cb}$ occurrence frequency is reduced by half from the deepening stage (Figs. 9a,b, second column), accompanied by a large reduction in the mid- to low-tropospheric positive Q2 (third column). Cs frequencies are reduced slightly from the deepening stage, accompanied by slight decreases in upper-tropospheric positive Q2 and midtropospheric negative Q2. In the decaying stage, the probability distribution in $Q_{\mathrm{cnvg}} Q_{\text {advt }}$ space is weighted more heavily below the line of zero moisture flux convergence (the dotted line in Fig. 9c, first column) and the average $Q_{\text {cnvg }}$ is largely reduced to one-third of the value in the deepening stage, accompanied by a reduction in upward $\omega$ and the magnitudes of Q2 (Figs. 9c, fourth and third columns, respectively). Therefore, there are more abundant mid- and lowlevel clouds than high-level clouds.

\section{f. Post-cold front}

The PCF sector has positive probability anomalies in the $Q_{\text {cnvg }} Q_{\text {advt }}$ space below the line of zero moisture flux convergence (Fig. 10, first column). Although the moisture flux is divergent, the low occurrence frequencies of $\mathrm{Cb}$ during the deepening and neutral stages (Figs. 10a,b, second column) are related to the weak positive average $Q_{\text {cnvg }}$ (first column) and the associated weak ascending motions (fourth column). These convective features are accompanied by positive Q2 in the 600-800-hPa layer and moderate average precipitation rates (6-8 $\mathrm{mm} \mathrm{day}^{-1}$; Figs. 10a,b, third column). In the decaying stage (Fig. 10c), the average $Q_{\text {cnvg }}$ is further reduced (first column), and there are more abundant midlevel thick clouds (second column) accompanied by a reversal in vertical motion to have weak descents above $800 \mathrm{hPa}$ (fourth column). The reduction of highlevel stratiform clouds in all stages indicates that the convection is less organized than in the $\mathrm{WF}$ or $\mathrm{CF}$ sectors.

\section{g. Cold sector and polar air intrusion}

Both the CS and PA are regions of moisture flux divergence $\left(Q_{\text {cnvg }}+Q_{\text {advt }}<0\right)$. In the $Q_{\text {cnvg }} Q_{\text {advt }}$ space, PA has a probability distribution weighted nearer to the center (Fig. 12, first column) because it is the driest among all sectors, while the CS has positive anomalies 

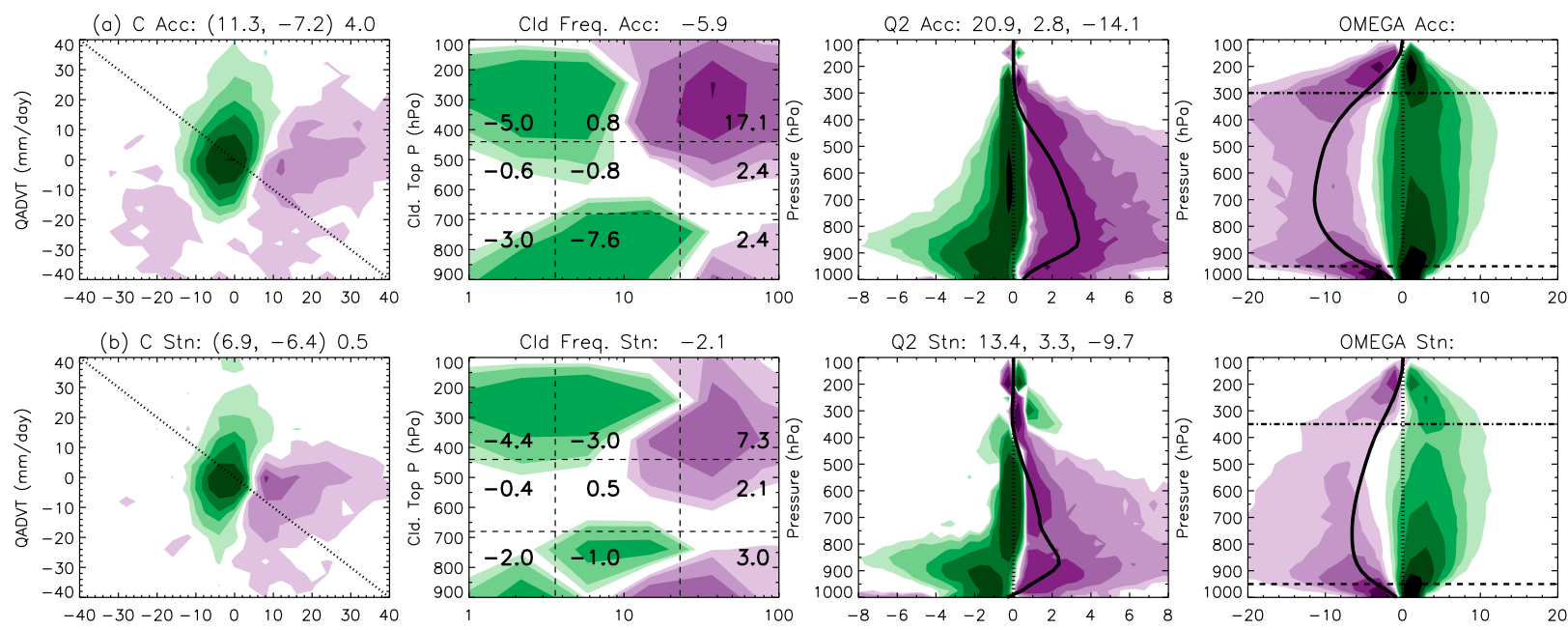

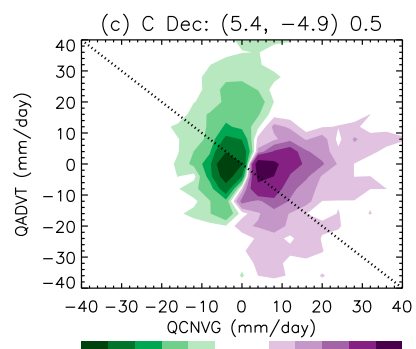

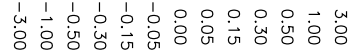

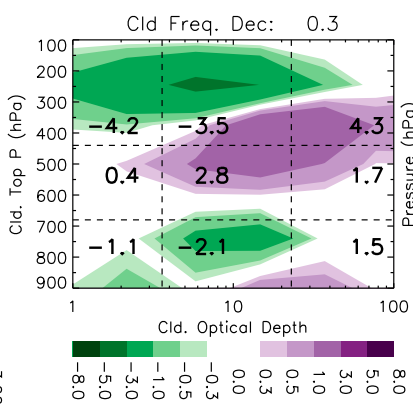

FIG. 13. As in Fig. 5, but for the $\mathrm{C}$ sector.
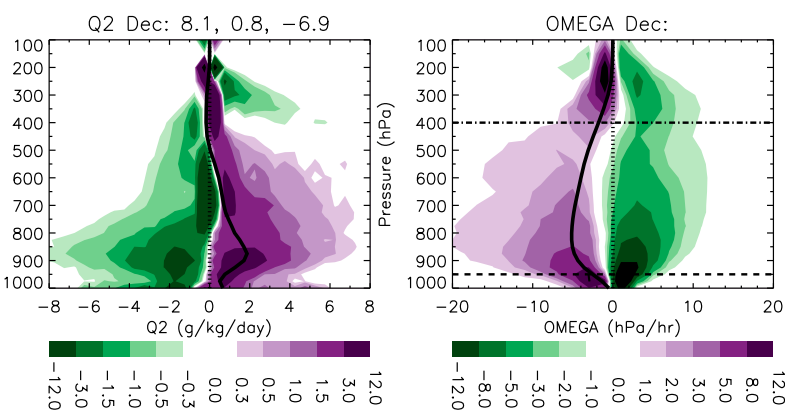

extending toward large negative $Q_{\text {advt }}$ (Fig. 11, first column). While both sectors are dominated by low- to midlevel clouds (Figs. 11, 12, second column; as also shown in Naud et al. 2016), the larger negative $Q_{\text {cnvg }}$ in the CS is associated with stronger descending motion (Figs. 11, 12, fourth column) and more clear conditions. Moreover, the stronger moisture flux divergence (Figs. 11, 12, first column) in the CS is also associated with stronger negative $\mathrm{Q} 2$ in the boundary layer (Figs. 11, 12, third column). This is consistent with the large ventilation of water vapor from the boundary layer behind the CF reported by Boutle et al. (2011). The inferred surface evaporation rate $\left(\sim 5-6.7 \mathrm{~mm} \mathrm{day}^{-1}\right)$ in the $\mathrm{CS}$ is larger than those in other sectors except the CF sector during the deepening stage.

The modulation during cyclone evolution is small for both the CS and PA (Figs. 11, 12). This is also indicated by the closeness of the CS and PA labels of different stages in Fig. 3.

\section{h. Center}

The C sector has positive anomalies in the $Q_{\mathrm{cnvg}} Q_{\text {advt }}$ space showing clear maxima situated on the $Q_{\text {cnvg }}$ axis, with tails extending toward the positive $Q_{\text {cnvg }}$ direction and the negative $Q_{\text {advt }}$ direction (Fig. 13, first column). The positive average $Q_{\mathrm{cnvg}}$ and the tails along the positive $Q_{\text {cnvg }}$ axis are associated with more upright ascending motions (Fig. 13, fourth column) aligned with more abundant $\mathrm{Cb}$ than $\mathrm{Cs}$ (Fig. 13, second column). The profiles of Q2 exhibit a greater weighting in the lower troposphere compared to the upper troposphere (Fig. 13, third column), implying that the clouds are more convective than stratiform. Average $P$ in the $\mathrm{C}$ sector is the largest among all sectors in ETCs, and this is largely maintained by the large $Q_{\text {cnvg }}$ and the negative $\partial Q / \partial t$ (Fig. 13, third column). The tails along the negative $Q_{\text {advt }}$ axis indicate midlevel medium to thick clouds in Fig. 4 (viz., As and Ns) as shown in the second column of Fig. 13.

The modulation by cyclone evolution is manifested as the shortening of both tails along the $Q_{\text {cnvg }}$ and $Q_{\text {advt }}$ directions, with the decaying stage exhibiting higher probability near the center (Fig. 13, first column). As the path of the label $\mathrm{C}$ in Fig. 3 moves closer to the center from deepening to decaying stages, the cloud frequency distributions in Fig. 4 imply a sharp decrease in $\mathrm{Cb}$ and an increase in As. 


\section{Variability in water budget and precipitation}

Average $Q_{\text {cnvg }}$ and $Q_{\text {advt }}$ in Figs. 5-13 (first column) are used as coordinates in the $Q_{\mathrm{cnvg}} Q_{\mathrm{advt}}$ space to represent phases of moisture flux convergence in different sectors and development stages of ETCs, as shown by the labels in Fig. 3. For each stage, the path of all sectors in the $Q_{\text {cnvg }} Q_{\text {advt }}$ space form a loop, with the sectors in the deepening stage (red labels) forming the largest loop and those in the decaying stage (blue labels) forming the smallest loop. Larger loops mean that the moisture flux convergence, together with other related quantities such as average $P$ and $\partial Q / \partial t$, has larger internal variability among the sectors.

The $P$ and $\partial Q / \partial t$ shown in Fig. 3 are obtained by averages in ETCs regardless of sectors and development stages. Therefore, the $P$ and $\partial Q / \partial t$ values predicted in Fig. 3 at the labels, which represent the sectors in different development stages, are different from the actual averages of $P$ and $\partial Q / \partial t$ shown in the third column of Figs. 5-13. The relationship between the values shown in Fig. 3 and the actual averages is shown in Fig. 14. The linear relationship indicates that the pathways depicted in Fig. 3 for the different sectors can serve as predictors for the water budgets of ETCs.

\section{Conclusions and discussion}

Phases of moisture flux convergence, described by a phase space spanned by moisture advection $\left(Q_{\text {advt }} \equiv\right.$ $-\mathbf{V} \cdot \nabla Q)$ and moisture dynamical convergence $\left(Q_{\text {cnvg }} \equiv\right.$ $-Q \nabla \cdot \mathbf{V}$ ) in Eq. (1) (Wong et al. 2016), modulate internal structures of precipitation and cloud-type combinations in extratropical cyclones (ETCs). When $Q_{\text {cnvg }}>0$, $P$ and deep convective cloud frequencies are mainly modulated by changes in $Q_{\text {cnvg }}$, while moisture tendency $(\partial Q / \partial t)$ is mainly modulated by changes in $Q_{\text {advt }}$ (Fig. 3). Therefore, the relative contributions of $Q_{\mathrm{advt}}$ and $Q_{\mathrm{cnvg}}$ to any given moisture flux convergence $\left(Q_{\text {advt }}+Q_{\text {cnvg }}\right)$ are related to how the converged precipitable water vapor (PWV) is utilized for increasing atmospheric water vapor or forming precipitation. They are, therefore, also connected to cloud-type combinations as summarized in Fig. 4.

When moisture flux convergence is primarily advective (average $Q_{\text {advt }}>0$ and $Q_{\text {cnvg }}$ is small), the converged PWV mainly acts to moisten the atmosphere rather than to form precipitation $(\partial Q / \partial t>P)$, and there are abundant high-level medium-thick (Cs) and thin (Ci) clouds together with low-level clouds. This is observed before the approach of the surface warm front (WF) in the pre-warm sector (PWS) of deepening ETCs. Gradual increases in $\mathrm{Q}_{\text {cnvg }}$, as in the pre-warm

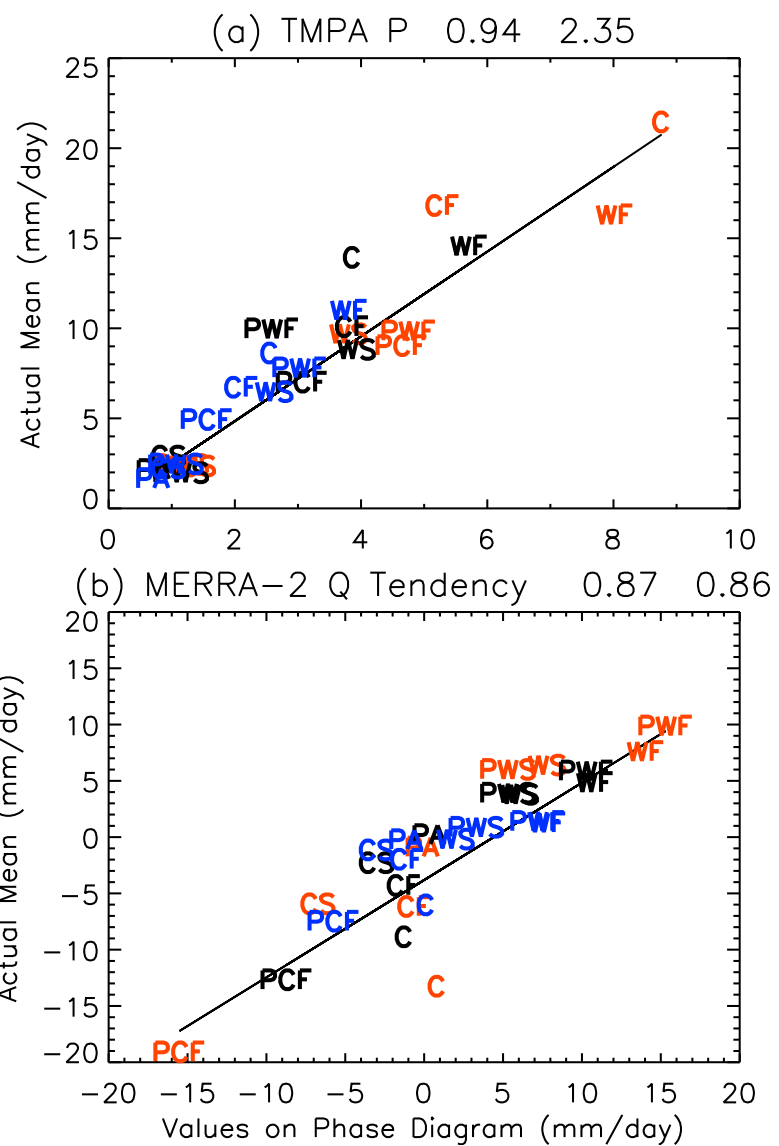

FIG. 14. Comparisons of (a) average $P$ (TMPA; $\mathrm{mm} \mathrm{day}^{-1}$ ) and (b) $\partial Q / \partial t$ (MERRA-2; mm day ${ }^{-1}$ ) between values shown in Fig. 3 and actual averages in each sector at each development stage from Fig. 5 to Fig. 13. The points are represented by the sector labels shown in Fig. 3 with cyclones of Acc, Stn, and Dec stages in red, black, and blue labels, respectively. The numbers in the title of each panel are the correlation and slope of the fitted lines.

front (PWF) sector and WF, are associated with increases in precipitation as well as the frequencies of both high-level, thick clouds $(\mathrm{Cb})$ and Cs. Reduction in both $Q_{\text {cnvg }}$ and $Q_{\text {advt }}$, as in the warm sector (WS), is associated with thinner high-level clouds and more frequent stratiform precipitation. We recall that passive sensors like MODIS prevent us from getting information of lowlevel clouds in the WS when abundant high-level clouds exist, while CloudSat/CALIPSO can detect clouds at lower levels in the WS (Naud et al. 2010).

In a regime of large positive $Q_{\text {cnvg }}$, large reduction in $Q_{\text {advt }}$ reduces Cs and Ci cloud frequencies and results in high-level cloud distributions weighing toward $\mathrm{Cb}$. When $Q_{\text {advt }}$ becomes negative with $Q_{\text {cnvg }}$ kept largely positive, the negative average $\partial Q / \partial t$ implies that precipitation formation is depleting the PWV. In this situation, there are more frequent $\mathrm{Cb}$ clouds than Cs clouds, and $\mathrm{Cb}$ clouds are more efficient in converting PWV to 


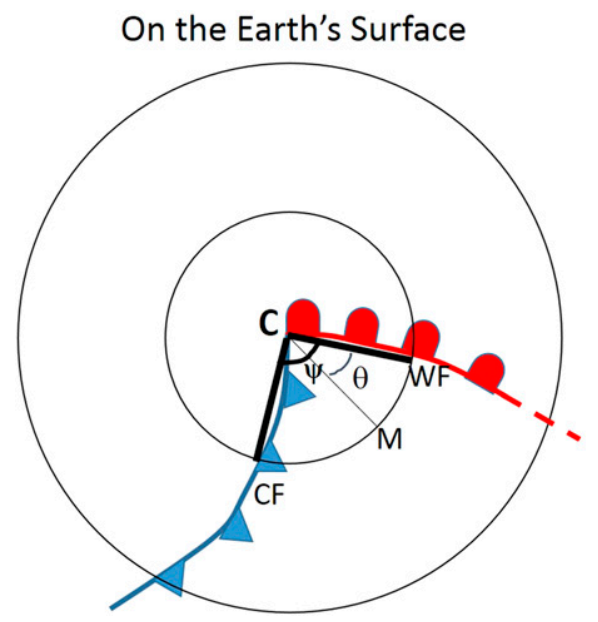

On the ETC Coordinate System

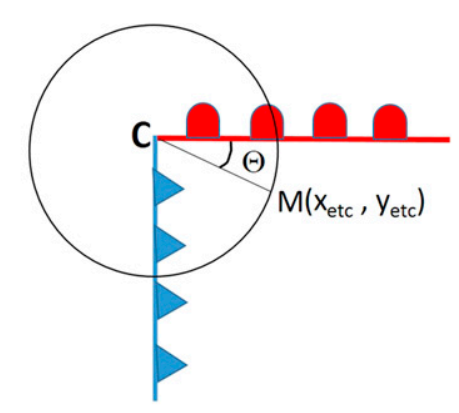

FIG. A1. A schematic diagram to show the mapping between the longitude-latitude coordinate system used on Earth's surface to the ETC coordinate system used to study ETCs. The cyclone center is marked by the label $\mathrm{C}$. The inner concentric circle centered at $\mathrm{C}$ intersects the surface warm front (red curve) at WF, and the surface cold front (blue curve) at CF. The thick black straight lines are geodesics linking WF and CF, respectively, to the center, with the angle $\psi$ between them. A point M on Earth's surface is mapped onto the ETC coordinates ( $x_{\mathrm{ETC}}$, $\left.y_{\text {ETC }}\right)$ as described in the appendix. The outer concentric circle intersects with only the cold front, and a geodesic (red dashed line) is extended from the end of the warm front to meet the circle.

precipitation than stratiform clouds. Such situation is observed in the cases of the cold front (CF) and center (C) sectors in deepening ETCs. Another equally important source of atmospheric moisture in the CF sector during the deepening state is surface evaporation, with rates comparable to those in the cold sector (CS).

The effect of changing moisture advection on modulating cloud-type combination can also be observed in the PWF and WF sectors during the ETC life cycle. From deepening to decaying stages, $Q_{\text {advt }}$ in these sectors is significantly reduced, while $Q_{\text {cnvg }}$ is marginally altered. The high-level cloud distribution shifts with more weighting toward thick clouds in these cases.

When $Q_{\text {cnvg }}$ is positive while $Q_{\text {advt }}$ is largely negative, the frequencies of $\mathrm{Cs}$ and $\mathrm{Ci}$ are largely reduced with some remnant of $\mathrm{Cb}$, indicating less organized convection as observed in the PCF sector. When the moisture flux convergence $\left(Q_{\text {cnvg }}+Q_{\text {advt }}\right)$ is largely negative, surface evaporation becomes important in the moisture budget with more occurrence frequencies of low-level clouds and "clear" sky as observed in the CS. A very dry condition will have the distribution in the $Q_{\mathrm{cnvg}} Q_{\text {advt }}$ space close to the center, as in the polar air intrusion (PA) sector, where thin midlevel clouds are observed.

Water recycling processes in ETCs are summarized as loops in the $Q_{\text {cnvg }} Q_{\text {advt }}$ phase space (Fig. 3). The most rapid recycling during the deepening stage is realized as the largest loop of phase changes in the $Q_{\mathrm{cnvg}} Q_{\mathrm{advt}}$ space, with the largest precipitation in the WF and CF sectors and the largest surface evaporation in the CF and CS. This is also related to the largest differences in extreme values (maximum minus minimum) of cyclone precipitation (Rudeva and Gulev 2011) and cloud radiative forcings (Polly and Rossow 2016). Since poleward transport of atmospheric moisture is mainly driven by transient eddy processes caused by ETCs, the extreme contrasts of $Q_{\text {advt }}$ in ETCs (i.e., moist advection in the PWF minus dry advection in the PCF) measure their efficiency in poleward moisture transport. Consequently, deepening cyclones are more efficient in poleward moisture transport.

The occurrence of midlatitude extreme precipitation is related to interannual variability in ETC activity (Ma and Chang 2017). Changes in $Q_{\text {cnvg }}$ are mainly responsible for such variability (E. Chang 2018, personal communication). Results from this study (Fig. 4) imply that more deep convective clouds are associated with these extreme events. Climate variability in ETC structures associated with extreme precipitation needs further study. It would also be interesting to investigate how distributions in the $Q_{\mathrm{cnvg}} Q_{\mathrm{advt}}$ space may change for ETCs in a warmer and moister future climate and how those correspond to cloud type and amount changes in ETCs.

We caution that the inability of the front detection technique to determine frontal occlusion may cause uncertainties in the properties of the WS and CF sectors, particularly in the decaying stage. How these factors 

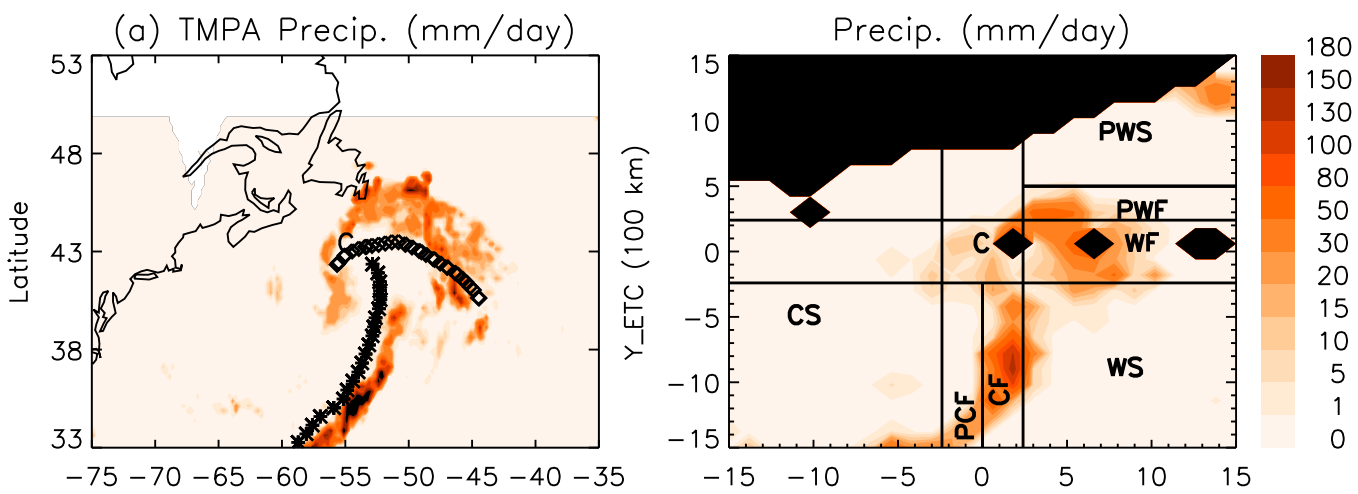

(b) $\operatorname{SLP}(\mathrm{hPa})$
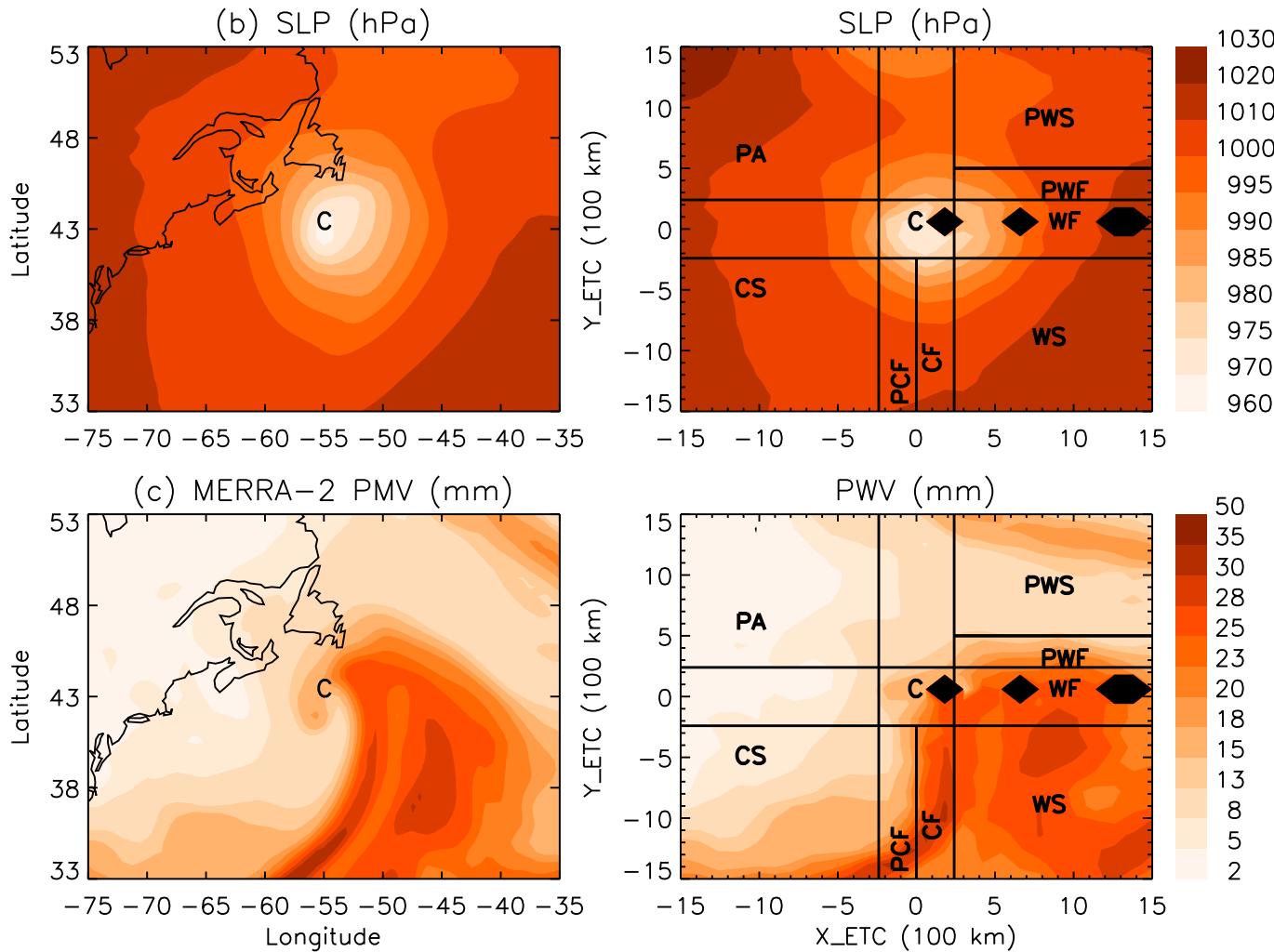

FIG. A2. An example of a deepening cyclone (left) before and (right) after the ETC coordinate transformation for (a) $P\left(\mathrm{~mm} \mathrm{day}^{-1}\right)$, (b) SLP (hPa), and (c) MERRA-2 PWV (mm). The cyclone center is marked with the label C, and the warm and cold fronts are indicated as diamonds and crosses, respectively, in (a). The nine sectors in the ETC coordinates are also labeled. Black areas indicate where data are missing in those particular ETC grid cells (recalling that TMPA $P$ is only available to $50^{\circ} \mathrm{N}$ ).

may influence the results with respect to the evolution of these two sectors also calls for further investigation. In addition, cyclone size is not considered in this study. We plan to incorporate scaling of cyclone size in the ETC coordinate transformation in the near future so that contamination of the environment surrounding the cyclones in compositing can be minimized.

Acknowledgments. The TMPA data can be downloaded from its webpage (Huffman et al. 2007; http:/ precip.gsfc.nasa.gov). The cyclone center database (Bauer et al. 2016; https:/gcss-dime.giss.nasa.gov/mcms) and the frontal database (Naud et al. 2010, 2016; https://data.giss. nasa.gov/storms/obs-etc) are available online. The research described in this paper was carried out at the Jet Propulsion Laboratory, California Institute of Technology, under a contract with the National Aeronautics and Space Administration. This work is supported by the NASA Precipitation Measurement Mission Science Team (PMM; NNN13D497T), and the NASA Making Earth 

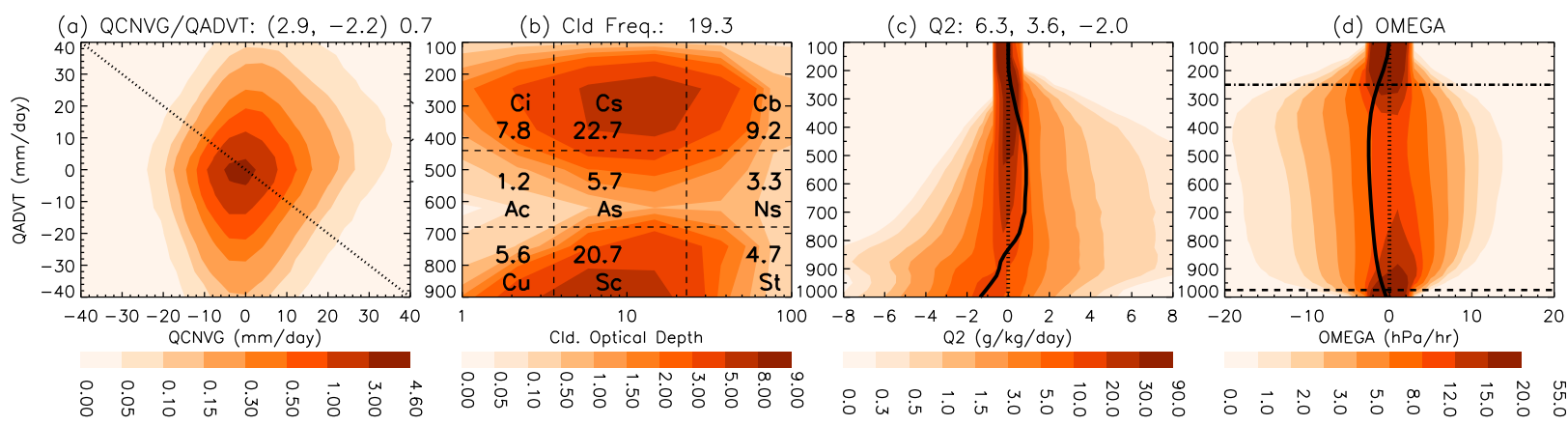

FIG. A3. As in Fig. 5, but for climatological histograms in (a) $Q_{\text {advt }}$ vs $Q_{\text {cnvg }}$ (\%), (b) CTP vs COD (\%), (c) Q2 profiles (\%), and (d) $\omega(\%)$. These histograms are counted for all samples of midlatitude oceanic cyclones regardless of sectors and development stages.

System Data Records for Use in Research Environments (MEaSUREs) projects. CMN is partially funded by NASA PMM Grant NNX16AD82G for this work.

\section{APPENDIX}

\section{ETC Coordinate Transformation and Climatological Histograms}

This appendix documents the mapping from any point within $1500 \mathrm{~km}$ from the $\mathrm{C}$ of an ETC to a point in the ETC coordinate. For each ETC, concentric circles are drawn at an interval of $60 \mathrm{~km}$ (about the spatial resolution of MERRA-2) around C. An arbitrary point $M$ in an ETC (Fig. A1) is mapped onto the ETC coordinate by scaling its relative angular distances from the $\mathrm{WF}$ and $\mathrm{CF}$, while keeping its distance from $\mathrm{C}$ unchanged.

First, we identify the circle that passes $\mathrm{M}$ and its intersections with the WF and CF (Fig. A1). The angle $\theta$ between $\mathrm{M}$ and WF is the angle between the two geodesics connecting $\mathrm{M}$ and $\mathrm{WF}$ to $\mathrm{C}$. The angle $\psi$ is the angle between the two geodesics connecting WF and $\mathrm{CF}$ to $\mathrm{C}$, representing the angle spanning between the two fronts for this particular circle. The point $\mathrm{M}$ on Earth's surface is mapped to the ETC coordinate by keeping the distance $\mathrm{CM}$ fixed and scaling the angle $\Theta$ between M and the $x$ axis (the WF direction) as

$$
\Theta=\theta \frac{\left(-\frac{\pi}{2}\right)}{\psi},
$$

where $-\pi / 2$ is the angle between WF and CF in the ETC coordinates. Then the coordinates $\left(x_{\mathrm{ETC}}, y_{\mathrm{ETC}}\right)$ are calculated as

$$
x_{\mathrm{ETC}}=\mathrm{CM} \cos \Theta \text { and } y_{\mathrm{ETC}}=\mathrm{CM} \sin \Theta .
$$

If the point $\mathrm{M}$ is outside the WS, the angle $\psi$ between the two fronts becomes a blunt angle instead of an acute angle, and $-\pi / 2$ in Eq. (A1) is replaced by $3 \pi / 2$.

For those circles intersecting with only one of the fronts (e.g., the CF in Fig. A1 for the outer circle), the end point of the other front (as in Fig. A1, the WF) is extended by a geodesic (the red dashed line in Fig. A1). The mapping of the points on these circles is then similar to that of M. For those circles intersecting no fronts, we do not perform the mapping and the data are discarded. In this way, all points with concentric circles passing through them intersecting at least one of the fronts are mapped one-to-one onto the ETC coordinate. Although the angular distances between any two points on a concentric circle are distorted, different sectors in ETC are efficiently defined in the ETC coordinate as shown in section 4.

Figure A2 shows an example of a deepening cyclone before and after the ETC coordinate transformation. In this example, the WF and CF do not intersect at the C. The area sandwiched between the WF and CF is transformed into the WS, and the portion of WF between the $\mathrm{C}$ and the intersection is transformed into the $\mathrm{C}$ sector. Cyclonic features of SLP and PWV are preserved after the coordinate transformation, although the orientation is rotated to fit the axes of ETC coordinate. When the occluded front is long and not all included in the $\mathrm{C}$ sector, the occluded front is usually identified as a WF, and the $\mathrm{CF}$ is extended by a geodesic to the $\mathrm{C}$. The area sandwiched between the extended CF and the occluded front is identified as the WS. All area west of the extended CF and all area north (south) of the WF in the Northern (Southern) Hemisphere are identified as outside the WS. The assumption to extend CF using a geodesic may be the reason for the less distinguishable WS during the decaying stage.

For Figs. 5-13 in the text, the anomalies are calculated as deviations from the climatological histograms plotted in Fig. A3. 


\section{REFERENCES}

Ackerman, S. A., R. E. Holz, R. Frey, E. W. Eloranta, B. Maddux, and M. McGill, 2008: Cloud detection with MODIS. Part II: Validation. J. Atmos. Oceanic Technol., 25, 1073-1086, https:// doi.org/10.1175/2007JTECHA1053.1.

Bauer, M., and A. D. Del Genio, 2006: Composite analysis of winter cyclones in a GCM: Influence on climatological humidity. J. Climate, 19, 1652-1672, https://doi.org/10.1175/ JCLI3690.1.

—_, G. Tselioudis, and W. B. Rossow, 2016: A new climatology for investigating storm influences in and on the extratropics. J. Appl. Meteor. Climatol., 55, 1287-1303, https://doi.org/ 10.1175/JAMC-D-15-0245.1.

Bony, S., and Coauthors, 2015: Clouds, circulation, and climate sensitivity. Nat. Geosci., 8, 261-268, https://doi.org/10.1038/ ngeo2398.

Booth, J. F., C. M. Naud, and A. D. Del Genio, 2013: Diagnosing warm frontal cloud formation in a GCM: A novel approach using conditional subsetting. J. Climate, 26, 5827-5845, https:// doi.org/10.1175/JCLI-D-12-00637.1.

,$- \ldots$, and J. Willison, 2018: Evaluation of extratropical cyclone precipitation in the North Atlantic basin: An analysis of ERA-Interim, WRF, and two CMIP5 models. J. Climate, 31, 2345-2360, https://doi.org/10.1175/JCLI-D-17-0308.1.

Bosilovich M. G., and Coauthors, 2015: MERRA-2: Initial evaluation of the climate. NASA Tech. Memo. NASA/TM-2015104606/Vol. 43, 145 pp., https:/gmao.gsfc.nasa.gov/pubs/docs/ Bosilovich803.pdf.

Boutle, I. A., S. E. Belcher, and R. S. Plant, 2011: Moisture transport in midlatitude cyclones. Quart. J. Roy. Meteor. Soc., 137, 360-373, https://doi.org/10.1002/qj.783.

Browning, K. A., 1986: Conceptual models of precipitation systems. Wea. Forecasting, 1, 23-41, https://doi.org/10.1175/ 1520-0434(1986)001<0023:CMOPS > 2.0.CO;2.

Chang, E. K. M., and S. Song, 2006: The seasonal cycles in the distribution of precipitation around cyclones in the western North Pacific and Atlantic. J. Atmos. Sci., 63, 815-839, https:// doi.org/10.1175/JAS3661.1.

Chen, Y., and A. D. Del Genio, 2009: Evaluation of tropical cloud regimes in observations and a general circulation model. Climate Dyn., 32, 355-369, https://doi.org/10.1007/ s00382-008-0386-6.

Cordeira, J. M., F. M. Ralph, and B. J. Moore, 2013: The development and evolution of two atmospheric rivers in proximity to western North Pacific tropical cyclones in October 2010. Mon. Wea. Rev., 141, 4234-4255, https://doi.org/10.1175/ MWR-D-13-00019.1.

Crespo, J. A., and D. J. Posselt, 2016: A-Train-based case study of stratiform-convective transition within a warm conveyor belt. Mon. Wea. Rev., 144, 2069-2083, https://doi.org/10.1175/ MWR-D-15-0435.1.

Dacre, H. F., P. A. Clark, O. Martinez-Alvarado, M. A. Stringer, and D. A. Lavers, 2015: How do atmospheric rivers form? Bull. Amer. Meteor. Soc., 96, 1243-1255, https://doi.org/ 10.1175/BAMS-D-14-00031.1.

Dee, D. P., and Coauthors, 2011: The ERA-Interim reanalysis: Configuration and performance of the data assimilation systems. Quart. J. Roy. Meteor. Soc., 137, 553-597, https://doi.org/ 10.1002/qj.828.

Field, P. R., and R. Wood, 2007: Precipitation and cloud structures in midlatitude cyclones. J. Climate, 20, 233-253, https:// doi.org/10.1175/JCLI3998.1.
Frey, R. A., S. A. Ackerman, Y. Liu, K. I. Strabala, H. Zhang, J. R. Key, and X. Wang, 2008: Cloud detection with MODIS. Part I: Recent improvements in the MODIS cloud mask. J. Atmos. Oceanic Technol., 25, 1057-1072, https://doi.org/10.1175/ 2008JTECHA1052.1.

Gelaro, R., and Coauthors, 2017: The Modern-Era Retrospective Analysis for Research and Applications, version 2 (MERRA-2). J. Climate, 30, 5419-5454, https://doi.org/ 10.1175/JCLI-D-16-0758.1.

Govekar, P. D., C. Jakob, and J. Catto, 2014: The relationship between clouds and dynamics in Southern Hemisphere extratropical cyclones in the real world and a climate model. J. Geophys. Res. Atmos., 119, 6609-6628, https://doi.org/10.1002/2013JD020699.

Hewson, T. D., 1998: Objective fronts. Meteor. Appl., 5, 37-65, https://doi.org/10.1017/S1350482798000553.

Houze, R. A., Jr., and P. V. Hobbs, 1982: Organization and structures of precipitating cloud systems. Adv. Geophys., 24, 225315, https://doi.org/10.1016/S0065-2687(08)60521-X.

Huffman, G. J., and D. T. Bolvin, 2009: TRMM and other data precipitation data set documentation. Laboratory for Atmospheres, NASA Goddard Space Flight Center and Science Systems and Applications, 20 pp., https://pmm.nasa.gov/sites/ default/files/document_files/3B42_3B43_doc_V7.pdf.

— and Coauthors, 2007: The TRMM Multisatellite Precipitation Analysis (TMPA): Quasi-global, multiyear, combined-sensor precipitation estimates at fine scales. J. Hydrometeor., 8, 38-55, https://doi.org/10.1175/JHM560.1.

King, M. D., and Coauthors, 2003: Cloud and aerosol properties, precipitable water, and profiles of temperature and water vapor from MODIS. IEEE Trans. Geosci. Remote Sens., 41, 442458, https://doi.org/10.1109/TGRS.2002.808226.

- S. Platnick, W. P. Menzel, S. A. Ackerman, and P. A. Hubanks, 2013: Spatial and temporal distribution of clouds observed by MODIS onboard the Terra and Aqua satellites. IEEE Trans. Geosci. Remote Sens., 51, 3826-3852, https:// doi.org/10.1109/TGRS.2012.2227333.

Li, M., T. Woolings, K. Hodges, and G. Masato, 2014: Extratropical cyclones in a warmer, moister climate: A recent Atlantic analogue. Geophys. Res. Lett., 41, 8594-8601, https://doi.org/ 10.1002/2014GL062186.

Ma, C.-G., and E. K. M. Chang, 2017: Impacts of storm track variations on winter time extreme weather events over the continental United States. J. Climate, 30, 4601-4624, https:// doi.org/10.1175/JCLI-D-16-0560.1.

Marchand, R., T. Ackerman, M. Smyth, and W. B. Rossow, 2010: A review of cloud top height and optical depth histograms from MISR, ISCCP, and MODIS. J. Geophys. Res., 115, D16206, https://doi.org/10.1029/2009JD013422.

Menzel, W. P., and Coauthors, 2008: MODIS global cloud-top pressure and amount estimation: Algorithm description and results. J. Appl. Meteor. Climatol., 47, 1175-1198, https:// doi.org/10.1175/2007JAMC1705.1.

Naud, C. M., A. D. Del Genio, M. Bauer, and W. Kovari, 2010: Cloud vertical distribution across warm and cold fronts in CloudSat-CALIPSO data and a general circulation model. J. Climate, 23, 3397-3415, https://doi.org/10.1175/ 2010JCLI3282.1.

, D. J. Posselt, and S. C. van den Heever, 2012: Observational analysis of cloud and precipitation in midlatitude cyclones: Northern versus Southern Hemisphere warm fronts. J. Climate, 25, 5135-5151, https://doi.org/10.1175/JCLI-D-11-00569.1.

, J. F. Booth, D. J. Posselt, and S. C. van den Heever, 2013: Multiple satellite observations of cloud cover in extratropical 
cyclones. J. Geophys. Res. Atmos., 118, 9982-9996, https:// doi.org/10.1002/jgrd.50718.

, D. J. Posselt, and S. C. van den Heever, 2015: A CloudSatCALIPSO view of cloud and precipitation properties across cold fronts over the global oceans. J. Climate, 28, 6743-6762, https://doi.org/10.1175/JCLI-D-15-0052.1.

—, J. F. Booth, and A. D. Del Genio, 2016: The relationship between boundary later stability and cloud cover in the postcold-frontal region. J. Climate, 29, 8129-8149, https://doi.org/ 10.1175/JCLI-D-15-0700.1.

Pfahl, S., and H. Wernli, 2012: Quantifying the relevance of cyclones for precipitation extremes. J. Climate, 25, 6770-6780, https://doi.org/10.1175/JCLI-D-11-00705.1.

— tropical cyclone precipitation and intensity. Geophys. Res. Lett., 43, 1752-1758, https://doi.org/10.1002/2016GL068018.

Platnick, S., M. D. King, S. A. Ackerman, W. P. Menzel, B. A. Baum, J. C. Riedi, and R. A. Frey, 2003: The MODIS cloud products: Algorithm and examples from Terra. IEEE Trans. Geosci. Remote Sens., 41, 459-473, https://doi.org/10.1109/TGRS.2002.808301.

Polly, J. B., and W. B. Rossow, 2016: Cloud radiative effects and precipitation in extratropical cyclones. J. Climate, 29, 64836507, https://doi.org/10.1175/JCLI-D-15-0857.1.

Rossow, W. B., and R. A. Schiffer, 1999: Advances in understanding clouds from ISCCP. Bull. Amer. Meteor. Soc., 80, 2261-2288, https:// doi.org/10.1175/1520-0477(1999)080<2261:AIUCFI>2.0.CO;2.

Rudeva, I., and S. K. Gulev, 2011: Composite analysis of North Atlantic extratropical cyclones in NCEP-NCAR reanalysis data. Mon. Wea. Rev., 139, 1419-1446, https://doi.org/10.1175/ 2010MWR3294.1.

Schemm, S., H. Wernli, and L. Papritz, 2013: Warm conveyor belts in idealized moist baroclinic wave simulations. J. Atmos. Sci., 70, 627-652, https://doi.org/10.1175/JAS-D-12-0147.1.

Simmonds, I., K. Keay, and J. A. T. Bye, 2012: Identification and climatology of Southern Hemisphere mobile fronts in a modern reanalysis. J. Climate, 25, 1945-1962, https://doi.org/ 10.1175/JCLI-D-11-00100.1.

Stephens, G. L., and Coauthors, 2002: The CloudSat mission and the A-Train: A new dimension of space-based observations of clouds and precipitation. Bull. Amer. Meteor. Soc., 83, 17711790, https://doi.org/10.1175/BAMS-83-12-1771.
Wang, T., S. Wong, and E. J. Fetzer, 2015: Cloud regime evolution in the Indian monsoon intraseasonal oscillation: Connection to large-scale dynamical conditions and the atmospheric water budget. Geophys. Res. Lett., 42, 9465-9472, https://doi.org/ 10.1002/2015GL066353.

— E. J. Fetzer, S. Wong, B. H. Kahn, and Q. Yue, 2016: Validation of MODIS cloud mask and multi-layer flag using CloudSat-CALIPSO cloud profiles and a cross-reference of their cloud classifications. J. Geophys. Res. Atmos., 121, 11620-11635, https://doi.org/10.1002/2016JD025239.

Winker, D. M., M. A. Vaughan, A. Omar, Y. Hu, K. A. Powell, Z. Liu, W. H. Hunt, and S. A. Young, 2009: Overview of the CALIPSO mission and CALIOP data processing algorithms. J. Atmos. Oceanic Technol., 26, 2310-2323, https://doi.org/ 10.1175/2009JTECHA1281.1.

Wong, S., and A. Behrangi, 2018: Regime-dependent differences in surface freshwater exchange estimates over the ocean. Geophys. Res. Lett., 45, 955-963, https://doi.org/10.1002/ 2017 GL075567.

— E. J. Fetzer, B. H. Kahn, B. Tian, B. H. Lambrigtsen, and H. Ye, 2011a: Closing the global water vapor budget with AIRS water vapor, MERRA reanalysis, TRMM and GPCP precipitation, and GSSTF surface evaporation. J. Climate, $\mathbf{2 4}$ 6307-6321, https://doi.org/10.1175/2011JCLI4154.1.

,-- B. Tian, B. Lambrigtsen, and H. Ye, 2011b: The apparent water vapor sinks and heat sources associated with the intraseasonal oscillation of the Indian summer monsoon. J. Climate, 24, 4466-4479, https://doi.org/10.1175/2011JCLI4076.1.

— A. D. Del Genio, T. Wang, B. H. Kahn, E. J. Fetzer, and T. S. L'Ecuyer, 2016: Responses of tropical ocean clouds and precipitation to the large-scale circulation: Atmospheric water budget-related phase space and dynamical regimes. J. Climate, 29, 7127-7142, https://doi.org/10.1175/JCLI-D-15-0712.1.

Wu, L., S. Wong, T. Wang, and G. J. Huffman, 2018: Moist convection: A key to tropical wave-moisture interaction in Indian monsoon intraseasonal oscillation. Climate Dyn., 51, 36733684, https://doi.org/10.1007/s00382-018-4103-9.

Yettella, V., and J. E. Kay, 2017: How will precipitation change in extratropical cyclones as the planet warms? Insights from a large initial condition climate model ensemble. Climate Dyn., 49, 1765-1781, https://doi.org/10.1007/s00382-016-3410-2. 